NBER WORKING PAPER SERIES

\title{
GOVERNMENT GAINS FROM SELF-RESTRAINT: \\ A BARGAINING THEORY OF INEFFICIENT REDISTRIBUTION
}

\author{
Allan Drazen \\ Nuno Limâo \\ Working Paper 10375 \\ http://www.nber.org/papers/w10375 \\ NATIONAL BUREAU OF ECONOMIC RESEARCH \\ 1050 Massachusetts Avenue \\ Cambridge, MA 02138 \\ March 2004
}

We thank Stephanie Aaronson, Daron Acemoglu, David Austen-Smith, Elhanan Helpman, Helen Milner, Peter Murrell, Robert Schwab and participants at Harvard's Political Institutions and Economics Policy Conference (December 2003) and public finance seminar at the University of Maryland for useful comments. Shir Raz and Polina Vlasenko provided excellent research assistance. Allan Drazen wishes to thank the Jack and Lisa Yael Chair in Comparative Economics for financial support. The views expressed herein are those of the authors and not necessarily those of the National Bureau of Economic Research.

(C2004 by Allan Drazen and Nuno Limão. All rights reserved. Short sections of text, not to exceed two paragraphs, may be quoted without explicit permission provided that full credit, including $(\mathbb{C}$ notice, is given to the source. 
Government Gains from Self-Restraint: A Bargaining Theory of Inefficient Redistribution Allan Drazen and Nuno Limão

NBER Working Paper No. 10375

March 2004

JEL No. D7, F13, C70, H23

\section{ABSTRACT}

We present a bargaining model of the interaction between a government and interest groups in which, unlike most existing models, neither side is assumed to have all the bargaining power. The government finds it optimal to constrain itself in the use of transfer policies to improve its bargaining position. In a model of redistribution to lobbies, the government finds it optimal to cap the size of lump-sum transfers it makes below the unconstrained equilibrium level. With a binding cap on efficient subsidies in place, less efficient subsidies will be used for redistribution even when they serve no economic function. Analogously, if it must choose either efficient or inefficient transfers, it may find it optimal to forego use of the former if its bargaining power relative to the lobby is sufficiently low. Even if the lobby can bargain over the type of redistribution policy with the government, the inefficient policy may still be used in equilibrium. If policymakers are elected, rational fully informed voters may choose a candidate who implements the inefficient policy over one who would implement the efficient policy and may prefer the candidate with the lower weight on voter welfare We thus offer an alternative theory that explains why governments may optimally choose to restrict efficient lump-sum transfers to interest groups and replace them with relatively less efficient transfers.

\section{Allan Drazen}

The Eitan Berglas School of Economics

Tel Aviv University

Ramat Aviv

Tel Aviv 69978 ISRAEL

and University of Maryland, NBER, CEPR

drazen@post.tau.ac.il
Nuno Limão

University of Maryland

College Park, MD 20742

Limao@wam.umd.edu 


\section{Introduction}

Why might governments choose to use inefficient policies when more efficient ones are available for a similar purpose? Transfers to effect redistribution provide a very good example, one that is especially relevant due to the importance of redistribution as a function of government. Motivations for redistribution are well understood. It can arise from concern over equity or more generally as the political economy outcome due to voting or lobbying. The methods used for redistribution are much less well understood. Specifically, why do governments often use inefficient policies to redistribute income towards different special interest groups (SIG)? For example, governments universally use trade policy to redistribute income towards particular factor owners, with many models explaining which factor owners and sectors are more successful in this redistribution process. But, why is it carried out using tariffs, never a first-best instrument for redistribution, as opposed to a production subsidy? Similarly, why are production subsidies used for redistribution when, in the absence of production externalities, lump-sum payments would be more efficient? ${ }^{1}$

In this paper we offer an alternative theory that explains why governments may optimally choose to restrict efficient lump-sum transfers to SIG and replace them with relatively less efficient transfers. We consider a world in which the government values both social welfare and a good given by SIG. In exchange for the goods provided by the SIG the government can makes transfers potentially using one or more alternative policies that can be ranked in terms of their relative efficiency. The outcome is determined by bargaining.

Our basic argument may then be understood in two parts. We first show that if transfers are lump-sum and neither party has all the bargaining power, it will be optimal from the government's perspective to put a binding cap ex-ante on the lump-sum transfer it can offer. This cap improves the bargaining position of the government by limiting the maximum offer it will ever make for a given level of the good provided by the SIG. The second part of the argument is then to show that with a cap on efficient transfers in place, less efficient ones will be used for redistribution even when they serve no economic function. To put the argument another way, if these inefficient transfers were replaced by efficient ones, the government would be in a worse bargaining position and ultimately be worse off. Hence, the government preference for a cap on efficient transfers and the use of inefficient ones. We also justify why some relatively inefficient policy is always available to bargain over. The

\footnotetext{
${ }^{1}$ In reviewing the literature on the political economy of trade policy Rodrik (1995) states: "Of course trade policy is not the only, or even the most important, mechanism of redistribution used by governments. But practically all governments apparently use it for that purpose. A sufficiently general and convincing explanation for this phenomenon has yet to be formulated" (p.1476).
} 
most compelling argument is that a SIG can always find some government policy that it can benefit from and the government can't credibly rule out all of these ex-ante.

A special, but leading case of these results is one where the government can't set an optimal cap on the relatively efficient policy but can choose to either have a cap at zero or no cap at all. This is equivalent to asking whether, given a binary choice between two policies, a government will ever choose to completely forego the relatively efficient transfer and use only the inefficient one. To answer this we must consider two offsetting effects. Switching to the inefficient policy improves the government's bargaining position, as already described. However, the bargaining surplus available to the government and SIG is also reduced. If the government had all the bargaining power and therefore collected all the surplus it would never switch to the inefficient policy. But governments with sufficiently low bargaining power may choose to switch because the loss in surplus from switching is small, so that the effect on government bargaining position is likely to be the dominant effect. We provide a general condition that reflects this trade-off and can be used to determine a government's choice between a pair of policies that can be ranked in terms of their relative efficiency. We also verify that the condition can be satisfied for the policies we use to illustrate the results of the model: lump-sum transfers versus production subsidies.

The absence of lump-sum (i.e., efficient) transfers in practice suggests that the government faces this type of binary choice. In this case, we would observe no examples of explicit caps on efficient transfers to support our modeling mechanism of caps. This may be why we can only find indirect evidence for the use of caps that are potentially motivated by a politician's desire to improve its bargaining position.

We also consider the determination of caps or the type of policy itself by bargaining or elections. First, even if the SIG can bargain over the type of redistribution policy with the government (rather than it being chosen unilaterally by the government or exogenously specified) the inefficient policy may still be used in equilibrium. Second, if the policymaker is elected, rational fully informed voters who vote solely on the basis of what type of redistribution policy will be used in equilibrium may choose a candidate who implements the inefficient policy over one who would implement the efficient policy. In fact rational voters may prefer the candidate with the lower weight on voter welfare, because such a politician may be in a better bargaining position with organized lobbies and hence deliver higher welfare to unorganized groups. The full information nature of the electoral results contrasts with disguised transfer arguments where the electoral success of politicians favoring inefficient transfers requires imperfect voter information, which we discuss below. 
These results have a number of interesting implications. First, to constrain itself the government requires a commitment device even though no time consistency problem is present. Therefore the model provides a reason why governments choose to sign international agreements that would appear to have no tangible benefit other than to limit their policy options. Second, for the same reason of strengthening a government against special interest groups, fully informed, rational voters may choose policymakers who favor inefficient policies over those who favor efficient ones Third, the model generates a specific testable prediction. Namely that the probability of use of a relatively inefficient redistribution policy towards a lobby is positively correlated with its bargaining power relative to the politician. $^{2}$

\subsection{Some examples}

Here are some examples in line with our approach. Consider first caps on transfers, where one should keep two points in mind. First, since a government may face the choice of using lump sum transfers with no restrictions or not using them at all, observing only non-lump-sum (i.e., relatively inefficient) transfers in redistributing income may be consistent with the government choosing a cap, namely zero, on more efficient transfers. Second, it should not be surprising if the government does not officially state that the reason for such limits is to improve its own well being.

In terms of caps on transfers agricultural policy provides one example. In the 1930's the U.S. federal government initiated an agricultural policy with the objective of providing income support to farmers. Currently, expenditure on farm price and income support is about $\$ 18$ billion a year. Historically the transfers have been based on a variety of price distorting policies such as price supports, production subsidies and trade policies. In 1996 the Freedom to Farm Act introduced direct payments to farmers subject to annual caps stipulated for the 6 years until the legislation was due for revision. The 2002 Farm Security and Rural Investment Act tightened some of the payment limits in the 1996 Act and included a cap on individual programs. There is also a constraint on total expenditure under the program agreed to by the US in the context of the WTO. The recent changes in the US and the EU towards more efficient means of transfers to farmers may also provide some evidence that is consistent with the model's prediction. If the continuing decline of agriculture in GDP for the EU and US and of farmers' influence has translated into a loss of bargaining power relative to the government then the model predicts precisely that governments would optimally switch to more efficient transfer policies. ${ }^{3}$

\footnotetext{
${ }^{2}$ We use the terms lobby and special interest group (SIG) interchangeably.

3 "The 2002 Farm Act also requires the Secretary, 'to the maximum extent practicable, to adjust domestic commodity
} 
Welfare payments are often also subject to such limitations. Federal bloc grants to states for welfare payments are capped. For example TANF (Temporary Assistance for Needy Families) entitles States to fixed bloc grants and was implemented with a cap of $\$ 16.5$ billion annually for 6 years. One of the reported reasons for the adoption of the caps was to control the cost of the transfers under the program that it replaces, the AFDC. Another example is the Social Services Block Grant Program that is also subject to a cap of $\$ 1,700$ million in 2001 .

A potentially credible way for a government to commit to limits in the use of redistribution policies and thus improve its bargaining position against domestic lobbies is to be bound by international agreements that are costly to break. Here are some examples. The Stability and Growth Pact constrains European Union governments' budget deficits and debt levels. These constraints have been used to increase the government's leverage in negotiations with domestic interests as suggested by our model. In Portugal the government has used the Pact as a key argument to limit wage increases in the public sector when negotiating with unions ${ }^{4}$

Regional and multilateral trade agreements provide another important example of commitment, which can be partially explained by our model. The WTO allows countries to bind their tariffs at a ceiling level, under the threat of tariff retaliation if that commitment is broken. Similarly regional trade agreements allow a country to commit to a limit on its use of trade barriers. Moreover, currently one of the main concerns in trade agreements is that as the limits on tariffs and other basic measures of protection are set other, less efficient methods of redistribution, such as standards that discriminate against foreign products, are increasingly used. This is consistent with the prediction of our model that once the government commits to a limit on a redistribution policy the lobbies find and pursue redistribution via relatively less efficient ones.

\section{$1.2 \quad$ Literature}

Several arguments have been presented to explain why politicians use relatively inefficient means to redistribute income to SIG. Perhaps the most prominent is the "disguised" transfer argument put forward by Tullock (1983). When a policy is not ostensibly aimed at redistribution, those who bear the costs may be largely ignorant of the redistribution taking place and are thus less likely to oppose it, particularly if the policy also has some social welfare benefit. Coate and Morris (1995) elegantly

program expenditures to avoid exceeding allowable' WTO domestic support ceilings. The Uruguay Round Agreement on Agriculture put a maximum allowable level on trade-distorting domestic support programs, as measured by the aggregate measurement of support (AMS). The ceiling on the U.S. AMS fell from $\$ 23.1$ billion in 1995 to $\$ 19.1$ billion in 2000." Westcott, Young, and Price (2002), p. 10.

4 "Portugal Chafes Under the Yoke of Austerity" Financial Times Sep 25, 2002. 
formalize this idea. They consider a world in which transfers to SIG can be made as lump-sum cash payments or by building public projects, which benefit SIG, but also possibly the population as a whole. While cash transfers reveal that a politician is catering to SIG, uncertainty both about the social value of a project and about the motives of politicians allows politicians who favor SIG to disguise their redistributive intent.

Disguised transfer arguments make clear why inefficient transfers may be used if there is asymmetric information about the value of the project and the aims of politicians. Were there full information about the motives of politicians and the effects of policies, there could no disguising of redistribution. If done at all, redistribution to SIG would be done by efficient means. In contrast, information asymmetries about the function of a policy play no role in our model. Everyone knows exactly how much redistribution is taking place and who is benefitting. But despite full information we show that inefficient transfers can still arise in a political equilibrium. Moreover, because there is no disguised transfer motive in our model, the inefficient redistribution policy used need not have any social welfare value.

A second leading argument is that governments that want to reduce the amount of redistribution to SIG can do so by committing to using less efficient forms of transfers. This general type of argument has been presented by Rodrik (1986), Wilson (1990), and Becker and Mulligan (1998). For example, Becker and Mulligan consider competition over transfers between two interest groups that partially internalize the deadweight cost of taxation to provide these transfers. A less efficient tax system increases these deadweight costs and hence leads to lower total transfers in the equilibrium resulting from the interaction of SIG with one another. Inefficient policy is like "sand in their wheels".

In our model, the use of inefficient transfers also reduces total transfers, implying higher social welfare, with the government's desire to limit the amount transferred to SIG determining the type of transfers used. However, our approach is fundamentally different from that of Becker and Mulligan, and this difference in approach has important implications. First, we rule out lobby competition, which is the main source of their result. Second, in that paper, as well as in Becker (1983), the approach is to use a general "influence function", meant to be a reduced form of the political process. Its properties, it is argued, make it consistent with many political processes. This is seen, quite reasonably, as an advantage of this approach, as its predictions about the implications of policy inefficiency should therefore be similarly general. On the other hand, the approach leaves unanswered a key question: what policy is chosen in a political equilibrium? It is clear that a social welfare maximizing government may prefer inefficient to efficient means of redistribution, but will that be 
the policy outcome? The focus on competition between SIG, rather than between SIG and the government highlights the same point. In Becker and Mulligan, as in the other papers mentioned above, the effects of policies on the amount of redistribution in equilibrium is modeled, but not the choice of policy itself. In a sense, the government is in the background. ${ }^{5}$

In contrast, we consider a more structural model with a specific type of interaction between government and SIG. The government is an active player whose behavior is explicitly modelled. Hence, the policy choice is endogenous, allowing us to ask what redistribution policy will be used as a function of the bargaining power of government relative to SIG. Since the government benefits from the inefficient transfer policy and is in a position to implement it, the use of the inefficient policy is a characteristic of the political equilibrium. Moreover, even within our structural model some important results depend on the relative bargaining power. Therefore a general "influence function" approach may not capture certain important aspects and therefore fail to predict interesting outcomes.

Acemoglu and Robinson (2001) argue that political institutions cannot credibly commit to future policies, which will be determined by whomever has political power at the time the policy is actually determined. Political power is positively correlated with group size, and inefficient transfers may be especially effective in maintaining or increasing group size. For example, agricultural subsidies will keep farmers from moving into other sectors. Difficulties of committing to future policy may also help explain the use of inefficient forms of transfer if one believes that they are harder to reverse than efficient forms of transfer. In contrast, in our approach group size is assumed unchanged over time, with no effect of one type of policy versus another on group size. Hence, the key consideration in the Acemoglu-Robinson explanation play no role in our mechanism. ${ }^{6}$

In terms of the formal approach, the closest work to ours is Grossman and Helpman (1994), and Dixit, Grossman and Helpman (1997), who pioneered models of bargaining between government and SIG based on utility maximization. Our set-up parallels theirs, but with some crucial differences. Foremost among them is our assumption that neither side has all the bargaining power, in contrast to their "menu-auction" approach in which the SIG make take-it-or-leave-it offers to the government. We will show that this difference is crucial in a number of respects. For example, in their papers, competition among SIG to receive government transfers implies that more distortionary instruments may improve the bargaining position of the lobby. Competition among lobbies is not the driving force of our mechanism and in our model it is the government that can benefit from choosing relatively

\footnotetext{
${ }^{5}$ It also leaves unanswered why a social welfare maximizing government would ever make transfers to SIG at all.

${ }^{6}$ Other arguments are that specific types of transfers give political benefits that lump-sum transfers do not (Shepsle and Weingast [1981], Weingast, Shepsle, and Johnsen [1981], and Dixit and Londregan [1995]) or that the institutional details of the legislative process by which transfers are chosen is crucial (Fiorina [1981], Baron [1991]).
} 
more inefficient policies.

As we pointed out our model also provides a simple motivation for governments of small countries to constrain themselves by signing international agreements. Most explanations for countries signing such agreements rely on their role as a commitment device to overcome a time inconsistency problem (Staiger and Tabellini [1987], Maggi and Rodriguez [1998]). In contrast the government in our model does not face any of the typical time consistency problems. ${ }^{7}$

The paper is organized as follows. In the next section, we describe the economic setup and political economy interaction. Section 3 contains the basic results regarding how a government can increase its welfare by capping the use of the efficient redistributive policy. In section 4 we add an inefficient transfer and show how it will be used alongside the efficient transfer as a means of transferring income to SIG when it has no social value. In section 5 we derive a general condition for the government to opt for using only a relatively inefficient transfer policy and show when it is satisfied by the specific pair of policies we use. In section 6 we derive the equilibrium redistribution policy when we extend the model to allow either the lobby or voters to interact with the government in the initial stage. In the final section we summarize our results.

\section{The Model}

\subsection{Economic structure}

We consider a small open economy in which individuals are similar except, possibly, for different endowments of non-labor factors. We represent utility as:

$$
u \equiv x_{n}+\sum u_{i}\left(x_{i}\right)
$$

where the subutility functions, $u_{i}$, are twice continuously differentiable and strictly concave. The term $x_{n}$, represents the consumption of the numeraire good, $n$, which is produced using labor with a marginal product of unity. This along with the assumption of a fixed world price of $n$ at unity and a sufficiently large labor force fixes the wage at unity. The exogenous world price for other goods is $p_{i}$.

\footnotetext{
${ }^{7}$ Maggi and Rodriguez (1998) use a setup similar to Grossman and Helpman (1994), but do not allow SIG to have all the bargaining power, which is crucial for their results, as it is for ours. If the government of a small country has access only to tariffs when bargaining with SIG, they show it can gain from committing to free trade if it has low bargaining power. In our model there is no time inconsistency; the gain to the government from self-restraint (which might be achieved via international agreements) is explained by the improvement in its bargaining position relative to the lobby. Moreover, Maggi and Rodriguez are not interested in explaining the use of inefficient transfer policies, tariffs in their case. They simply assume that more efficient transfer policies are not present. In contrast, the main purpose of our paper is precisely to explain the use of less efficient transfer policies.
} 
For given prices an individual who owns the specific factor $i$ has income $E_{i}$ and chooses consumption to maximize utility subject to a budget constraint, $x_{n}+\sum_{i} p_{i} x_{i} \leq E_{i}$. Given the assumptions on the subutility, the budget constraint is satisfied with equality and individuals demand $d\left(p_{i}\right)=u^{\prime}\left(p_{i}\right)^{-1}$ of each of the non-numeraire goods. An individual's indirect utility is simply the sum of income, $E_{i}$, and consumer surplus $s(\mathbf{p})=\sum u\left(d\left(p_{i}\right)\right)-p_{i} d\left(p_{i}\right)$.

Production of the non-numeraire goods requires labor and a specific factor to be combined according to a constant returns technology. Since the wage is unity the return to the specific factor depends only on the supplier price of the good, $p_{i}^{s}$. The reward is given by the quasi-rent $\pi_{i}\left(p_{i}^{s}\right)$ and equilibrium output is $\pi_{i}^{\prime}\left(p_{i}^{s}\right)$. In the absence of production taxes, tariffs or trading costs $p_{i}^{s}=p_{i}$.

To redistribute income to lobbies of capital owners in sector $i$ the government may use combinations that include a lump-sum transfer, $T_{i}$, or other types of transfer, which for concreteness we summarize by a unit production subsidy, $t_{i} .{ }^{8}$ Transfers to lobbies are financed by lump-sum taxes charged on the voting population of $N$ individuals. We allow for a unit collection cost of $\beta \in(0,1)$, which is the same independently of whether it is spent as $T$ or $t$. We assume that the government balances its budget every period, so that a total transfer of $\tau$ requires the government to collect $\tau /(1-\beta)$. Total transfers are given by:

$$
\tau=\sum_{i} T_{i}+\sum_{i} t_{i} \pi_{i}^{\prime}
$$

An exogenously given set of sectors $L$ form lobbies and their gross welfare is:

$$
W_{i}=l_{i}+\pi\left(p_{i}+t_{i}\right)+T_{i}+\alpha_{i} N[s-\tau /(1-\beta) N] \quad \text { if } i \in L
$$

where $\alpha_{i}$ is the share of the voting population that owns factor $i$ and $l_{i}$ is their labor income.

Each lobby can transform some amount $C_{i}$ of the numeraire into a good that it offers to the politician in exchange for an increase in a transfer to itself, in the form of $T_{i}$ or $t_{i}$. We assume that factor ownership in any one particular lobby is sufficiently concentrated, i.e. $\alpha_{i}$ is sufficiently small, such that it takes the size of the budget, $\tau /(1-\beta)$, as given and does not lobby for it to be reduced. We do so to maintain our theory focused on the interaction between the government and the lobbies in the absence of any lobby competition effects. Thus the lobby maximizes its gross welfare net of

\footnotetext{
${ }^{8}$ Note that in a small open economy the consumer prices are determined by the world price so they are independent of the production subsidy. Production subsidies affect quantities produced and lowers individuals' income but this will only result in lower consumption of the numeraire good.
} 
its provision of lobby goods, which is given by:

$$
V_{i} \equiv W_{i}-C_{i}
$$

Social welfare is obtained by summing the indirect utility over individuals in and out of lobbies:

$$
W \equiv l+\sum_{i} \pi\left(p_{i}+t_{i}\right)+\sum_{i} T_{i}-\tau /(1-\beta)+N s
$$

The government objective is a weighted sum of social welfare and lobby provided goods.

$$
G \equiv a W+\sum_{i \in L} \Psi_{i}\left(C_{i}\right)
$$

where we assume that each lobby good is valued according to a function $\Psi$, which is twice continuously differentiable and strictly concave. We also assume that $\lim _{C \rightarrow 0} \Psi^{\prime}(C)=\infty$ and $\Psi(0)=0$. We model lobby goods as additively separable in the government's objective because it helps us to concentrate on the interaction between the government and the SIG, rather than on competition among SIGs. Additive separability and concentrated factor ownership $\left(\alpha_{i} \rightarrow 0\right)$ implies that there is no economic interaction among lobbies, so that it is clear that our results are not driven by lobby competition. Lobby competition is an interesting issue, but we want to look for important effects elsewhere. Moreover, in several instances interest groups lobby for policies such as production subsidies in their own sector so modelling away motives for lobby competition is not only convenient but also a plausible representation.

As we will see, the strict concavity of $\Psi$ is a technical assumption that ensures an interior solution in the benchmark case when only lump-sum transfers are used. ${ }^{9}$ But this formulation has a natural economic interpretation: the government values lobby goods in a way similar to the evaluation of private non-numeraire goods, $x_{i}$, by individuals. This interpretation of diminishing marginal utility of $C$ is reasonable if the SIG are providing not simply cash but goods or valuable services to politicians, as for example, in Drazen (2002). Concavity in each of the $C_{i}$ is consistent it being a "good" that can be supplied only (or primarily) by that lobby. ${ }^{10}$

\footnotetext{
${ }^{9}$ When $C$ enters the government's objective function linearly, there will be a corner solution in the trade of $C$ for $T$. In the corner solution in which $T$ (and $C$ ) are zero, then inefficient transfers $t$ will be zero as well. Further, as will be clear below, our assumption that the marginal inefficiency of $t$ rises as $t$ rises implies that concavity of $\Psi(\cdot)$ is not necessary for the Pareto frontier with inefficient transfers to be concave.

${ }^{10}$ This is primarily to ensure the additive separability and model away lobby competition. However, there may be examples where this formulation is reasonable such as when a geographically concentrated lobby ensures the turnout of members in a local event or election. Another example is given by Vlasenko (2003) who argues that privatized firms in Russia keep employment high in their sectors or regions in exchange for legal barriers preventing the entry of new
} 


\subsection{Political structure}

The structure and timing of the interaction between the government and lobbies is as follows. In an initial stage the government chooses a cap on the amount of the transfers it can make or which of the redistribution policies it will use. ${ }^{11}$ In the second stage the government and each of the lobbies bargain over a level of the lobby provided good and government transfers. The additive separability and concentrated factor ownership for organized groups eliminates the interaction across lobbies and so we drop the subscript $i$ and discuss the results relative to a given SIG. We model the outcome of the interaction in the second stage as the solution to a Nash bargaining problem. We can interpret this solution as a bilateral game of alternating offers with an exogenous, constant risk of breakdown of negotiations in each round or if players discount the future (Binmore, Rubinstein, and Wolinsky [1986]). We do not specify the institutional structure which might imply a game of alternating offers, but we would argue that the "give-and-take" that such a game is meant to represent is a key feature of the interaction of politicians and lobbyists. ${ }^{12}$

A key feature of the bargaining process is that neither side has all the bargaining power, that is, neither side can make a "take-it-or-leave-it" offer. This is in contrast to Grossman and Helpman (1994) and Dixit, Grossman, and Helpman (1997), in which the lobbies can make a take-it-or leave-it offer in the form of a "menu" of contributions in exchange for different levels of a policy instrument. At the other extreme, is the veto player model of Drazen (2002) that assumes the government chooses the policy vector, which SIG can either accept or reject. Our assumption that neither side has all the bargaining power is necessary for the key results and highlights the importance of considering alternatives to the extremes represented by the government or lobby as veto players.

\section{Benchmark case: Efficient Transfers}

We begin with a benchmark case where only lump-sum transfers are available to show that the government optimally chooses to cap it below the unconstrained solution. Figure 1 illustrates the unconstrained solution. The vertical axis denotes lobby goods to the politician, the horizontal axis transfers to the lobby. The line $V^{0}$ represents the lobbies' reservation utility, i.e. when it provides none of the lobby good and receives no transfer. From (3) and (4), the lobby is indifferent between providing the lobby good and receiving an efficient transfer of the same amount so the slope of firms.

${ }^{11}$ In section 6 we discuss a more general formulation where the adoption of caps or choice of inefficient policies in the first stage is subject to a popular vote or to bargaining with lobbies.

${ }^{12}$ In our working paper, we show that proposition 1 also holds under the Kalai-Smorodinsky bargaining solution. 
$V$ is unity since we are assuming that $\alpha$ goes to 0 . Any movements towards the southeast leave the lobby better off. The government's reservation utility is denoted by $G^{0}$. It is upward sloping because the negative effect of a transfer paid to the lobby (due to the cost of raising tax revenues) must be compensated by an increase in the lobby good received. The slope is increasing because we assume that $\Psi$ is concave to ensure an interior solution. Movements to the northwest improve the government's welfare. If the marginal rate of substitution of lobby goods for transfers is lower for the government then the lobby at the origin then lobbying will be "politically efficient". This is satisfied given our assumption on $\Psi^{\prime} .^{13}$

The segment $g^{m} v^{m}$ in Figure 1 that defines the contract curve is horizontal because $G$ and $V$ are quasilinear in $T$. Therefore, provided the transfer is in the range $\left[T^{0}, T^{1}\right]$, that is provided that both the lobby and government are assured their reservation utilities, the unconstrained level of the lobby good, $C^{N}$, is simply determined by the following efficiency condition

$$
\begin{aligned}
\frac{G_{T}}{G_{C}} & =\frac{V_{T}}{V_{C}} \\
\Psi^{\prime}\left(C^{N}\right) & =\frac{a \beta}{1-\beta}
\end{aligned}
$$

where $G_{T}$, etc. are partial derivatives. Thus, as expected, the equilibrium level of lobby goods provided is decreasing with respect to the weight that the politician places on social welfare, $a$, and the cost of collecting taxes, $\beta$.

To determine the equilibrium level of the lump-sum transfer we must consider the division of the surplus that arises from the Nash bargaining solution.

$$
\begin{aligned}
& \operatorname{Max}_{G \geq g^{0}, V \geq v^{0}} U=\left(G-g^{0}\right)^{\gamma}\left(V-v^{0}\right)^{1-\gamma} \\
& \text { s.t. } G=g^{m}-\frac{a \beta}{1-\beta}\left(V-v^{0}\right)
\end{aligned}
$$

Given that the Pareto frontier given by (9) is linear the solution can be written as

$$
\begin{aligned}
& g^{N}-g^{0}=\gamma\left(g^{m}-g^{0}\right) \\
& v^{N}-v^{0}=(1-\gamma)\left(v^{m}-v^{0}\right)
\end{aligned}
$$

Of the total surplus that is potentially available to the government over its reservation utility, it receives a share proportional to its bargaining power, $\gamma$. Similarly for the lobby. It is then simple to

\footnotetext{
${ }^{13}$ The precise condition is $a \beta /(1-\beta) \Psi^{\prime}(0)<1$, which is satisfied because $\lim _{C \rightarrow 0} \Psi^{\prime}(C)=\infty$.
} 
solve for the bargained level of the efficient transfer, $T^{N}$.

We now allow the government to cap the efficient transfer. No alternative transfer policies are yet available, an assumption which we relax in the next section. The timing of actions is the following. In the first stage the government chooses the cap $T^{c}$ to maximize its objective function, $G\left(C^{N c}\left(T^{c}\right), T^{N c}\right)$. In the second stage the government and lobby bargain over the lobby good $C^{N c}$

and the level of the transfer $T^{N c} \leq T^{c}$, taking the cap as given. Our objective is to show that the subgame perfect equilibrium level of the cap $T^{c}$ strictly binds, i.e. that the government is strictly better off by setting a cap below the unconstrained transfer previously derived.

Solving backwards suppose that the cap is given by $T^{c}$ in Figure 2. The contract curve is now defined by the kinked segment $g^{m c} v^{m c}$. Note that if the cap is greater than or equal to $T^{0}$, the transfer consistent with government utility level $g^{m}$, then the government can still assure the lobby its reservation utility, $v^{0}$, and therefore the government's maximum utility is unchanged relative to the unconstrained solution. But for the cap to be binding it must be strictly less than $T^{N}$ and therefore the maximum utility for the lobby is lower than $v^{m}$ as shown in Figure 2.

At the point where the cap binds, the lobby can only be made better off by reducing its provision of the lobby good to the government. Relative to the unconstrained solution it is feasible to find solutions such as $N^{c}$, which leave the government better off then $N$. Proposition 1 shows that a binding cap leaves the government strictly better off and therefore would be optimally chosen by the government in the first stage.

\section{Proposition 1 :}

In the absence of alternative transfer policies to lobbies the government chooses a cap on the efficient transfer that is strictly binding at $\left(C^{N}, T^{N}\right)$ iff neither player has all the bargaining power.

\section{Proof: See Appendix}

To understand the basic intuition for this result note that the cap limits the maximum utility a lobby can obtain from dealing with the government. More importantly, by setting a cap that binds at the unconstrained Nash solution the government credibly commits to transferring less $\operatorname{than} T^{N}$ in exchange for $C^{N}$. It is this commitment to a lower transfer that explains why the cap improves the government's bargaining position. This improvement in bargaining position can also be interpreted as an improvement in the government's terms-of-trade. By constraining its supply of transfers that are to be traded for the lobby good the government improves its own terms-of-trade. 
Graphically the improvement in the government's bargaining position is captured by a steeper Pareto frontier, as shown in figure 4. The dashed straight line represents the frontier in the benchmark case, (9), point $N$ is the unconstrained Nash solution. The constrained frontier coincides with the original until the cap binds, after which point the lobby can only be made better off by offering less $C$. This has an increasing cost for the government given the concavity of $\Psi($.$) , hence the concave$ Pareto frontier. Using this we can show that the government can always find a binding cap that leaves it strictly better off, $N^{c}$, relative to the unconstrained solution, $N$, provided $\gamma \in(0,1)$.

The cap also raises social welfare, which may be seen as follows. Government utility is $G=$ $a W+\Psi(C)$. Since a cap increases government's utility $G$ and unambiguously lowers $C$ (and hence $\Psi(C)$ ), it must unambiguously raise social welfare $W$. This may also be seen directly. The only effect of the cap on consumers is via the taxes they must pay to finance transfers. The fall in the equilibrium level of transfers relative to the unconstrained solution that is induced by the cap reduces taxes. Since taxes are costly to raise, the cap unambiguously increases social welfare.

The proposition also makes clear the importance of allowing for a more general distribution of bargaining power between the government and the lobby. There is no strict gain for the government from setting a cap if it has neither all nor none of the bargaining power. Thus political economy approaches that focus on take-it-or -leave-it offers by the government or by the lobby completely miss the insight in this proposition.

\section{Inefficient and Efficient Transfers}

We now expand the policy space to allow for transfers that are not lump-sum. We show that the government continues to set a cap on the efficient transfer and, more importantly, that the equilibrium will feature redistribution that uses the relatively inefficient policy.

Inefficient transfers to producers can occur via numerous instruments of industrial policy such as loan guarantees, tax breaks, unit production or export subsidies, price supports, etc. Even in the absence of lobbying, a welfare maximizing government may want to use the production subsidy, for example, as a way to correct a production externality. Hence, a government may choose not to cap or outright prohibit the use of a production subsidy, even if it were feasible to do so. Evidence for this is found in the WTO agreement on subsidies, which rules out the use of production subsidies targeted at firms or industries but it allows subsidies aimed at correcting market failures, e.g. if they are aimed at education, infrastructure or R\&D. In our working paper, we explicitly consider the case in which a production subsidy may be used to address a production externality whose size may 
vary over time, in order to motivate the optimality of not capping the inefficient transfer at zero. Moreover, in practice, it may not be possible for the government to prohibit every possible form of inefficient transfer. Both in this last case or when the policy can be used to correct an externality the government leaves itself open to credible lobby offers of lobby goods in exchange for further transfers, which are potentially less efficient.

For concreteness, we consider the case of a production subsidy, which allows us to show unambiguously that the inefficient transfer is used when $T$ is optimally capped. Considering production subsides may be further justified either by their pervasiveness in several countries or because they represent a simple summary measure for different type of production related policies. To show clearly what is driving our results, we deliberately rule out any economic function for the subsidy, so that its optimal social level is zero. Therefore it is known that production subsidies are used only for redistribution and there is never a benefit for politicians to use them as disguised transfers. Such a benefit may exist, as argued by Tullock (1983) and Coate and Morris (1995), and could clearly be modelled here but doing so would confuse the source of our result.

\subsection{A formal definition of inefficiency}

When the interaction between government and lobbies involves possible welfare gains for both when transfers are exchanged for lobby goods, we may ask what does it mean to say a transfer is "inefficient"? And, how does it relate to the economic functions (or lack of them) of transfers? The following definition (and related Lemma 1 in the appendix) addresses these questions.

Definition: Policy $t$ is an inefficient transfer policy relative to $T$ iff there are no joint political gains from trade between the government and lobby by lowering $T$ and increasing $t$ above the social welfare maximizing level of $t \equiv t^{e x t}$. That is $t^{*}=t^{\text {ext }}$ where $\left\{T^{*}, t^{*}\right\} \equiv \operatorname{argmax}_{T, t}(G((\bar{C},)+.V(\bar{C},)$.$) .$

The social welfare maximizing value for $t$ is zero in the absence of externalities. This definition then requires that no joint gains are possible from using $t$ as a transfer to partially replace $T$, the lump-sum transfer.

The importance of this definition of inefficiency becomes clearer if we consider an externality that

can be corrected by using $t$. In this case, the social optimum requires $t^{\text {ext }}>0$ and $t$ would not be an inefficient policy according to the definition above. We show this formally in the appendix. Intuitively, when there is an externality and $t=t^{e x t}$ the marginal social cost of increasing $t$ is close to zero but the marginal benefit to the lobby in this sector is strictly positive since it is already 
receiving the subsidy. Hence, when the policy has a social value, observing a value of $t$ greater than the social welfare optimum $t^{e x t}$ implies that the government is making a transfer but also that it is actually using an efficient policy for that transfer, at least at the margin. Therefore, one must be careful when using the disguised transfer argument as a general explanation for the use of inefficient policies, as that only applies in periods or states of nature in which the externality is not present. ${ }^{14}$

\subsection{Equilibrium with inefficient transfers}

The timing of the two-stage game is the same as before. In the first stage, the government commits to a maximum level of the lump-sum transfer, $T^{c}$ in order to maximize its objective (6). As discussed above we assume that the government is either unable to put a cap on the efficient transfer or does not find it optimal to do so. ${ }^{15}$ In the second stage, the government and lobby bargain over the level of lobby goods and the level of transfers, $T$ and $t$. In the appendix we present a formal definition of the equilibrium.

We now analyze the equilibrium beginning with the second stage, which is represented in Figure 4. The dashed line represents the Pareto frontier if there were no caps set on $T$. Therefore it is identical to Figure 4 up to the cap level, $T^{c}$ because, in the absence of any externality, $T$ is more efficient than $t$ and thus it will be the policy used until the cap binds. Any further transfers by the government to the lobby must then occur in the form of the production subsidy. The Pareto frontier when a cap is set on $T$ and the production subsidy is used is concave, at least for small values of $t .^{16}$ This implies that the government gains from setting a cap on $T$ as shown in proposition 1 . In proposition 2 we show the concavity formally but intuitively it is due to the following. First, because the subsidy is inefficient relative to the lump-sum transfer the Pareto frontier when $t$ is used lies below the dashed line. Second, this inefficiency disappears when $t=0$ and thus the slopes of the Pareto frontier when there is no cap on $T$ and the new frontier are identical at $t=0$. Third, for the same reason, the new Pareto frontier is continuous with the frontier when there is no cap on $T$ at $t=0$.

Consider now the first stage. We will show that the government gains by putting a cap on the efficient transfer and that in the resulting equilibrium, positive values of the inefficient transfer are

\footnotetext{
${ }^{14}$ This issue need not arise in Coate and Morris (1995) because they have valuation of the project that is discretely different in each of two states. They show that the project may be built even in the state where it is socially inefficient to do so.

${ }^{15}$ In our working paper, we show that the government's optimal cap for the inefficient transfer $t$ is strictly positive when it addresses a time-varying production externality. We also show that $t$ is used for redistribution even if in that period there is no externality, i.e. when $t$ is inefficient.

${ }^{16}$ In the figure drawn we implicitly assume that the Pareto frontier when $T$ is capped and $t$ used is everywhere concave. This is not essential for the results, concavity for small values of $t$ is sufficient and satisfied. In the appendix we present the condition for the Pareto frontier to be globally concave.
} 
used. $^{17}$ The basic intuition for the cap on the efficient transfer policy is similar to that in Proposition 1. The government gains from the commitment to make a lower offer. In fact most of the previous proposition applies directly after we show that the constrained Pareto frontier when $t$ can be used is concave.

\section{Proposition 2 :}

In the political equilibrium, there is:

a. a cap on the efficient transfer, $T$, that is strictly binding iff neither player has all the bargaining power; and

b. use of the relatively inefficient transfer policy, $t$.

\section{Proof: See Appendix}

The proposition shows that if the government can cap the efficient policy it will do so even in the presence of alternative less efficient policies. This is perhaps not surprising given proposition 1 , since the intuition is in fact the same: the cap allows the government to credibly commit to a lower offer. The observation that as $t \longrightarrow 0^{+}$, we have $G_{t} / V_{t}=G_{T} / V_{T}$, is important to show that the frontier is strictly concave when we allow for production subsidies.

The second part of the proposition is less obvious. Why is the government making inefficient transfers in equilibrium? Why not simply increase the cap and make a similar value transfer using the efficient policy? Doesn't that leave the lobby better off and thus willing to provide more lobby goods, which in turn would leave the government better off? This argument captures only the increase in the Pareto set from relaxing the cap. However, this will not translate into an increase in government welfare because relaxing the cap reduces the government's ability to make a credible offer of a low transfer, as shown in proposition 1. Thus the government will not relax the cap.

This is the key conceptual result. By constraining what it is able to offer SIG, the government can improve its bargaining position in the trade of lobby goods it covets for the transfers that SIG desire. In the presence of such a constraint, the partial substitutability of a second inefficient transfer for the more efficient type of subsidy ensures that it will be used in equilibrium. The inefficiency of the second transfer relative to the first partially "protects" the gain in the bargaining position

\footnotetext{
${ }^{17}$ As before, the cap on the efficient form of transfer will also increase social welfare if $C$ falls, since $G=a W+\Psi(C)$. However, when the form of the inefficient transfer is a production subsidy per unit produced, it is theoretically possible that $C$ could rise, since the marginal benefit of $t$ to the lobby is $\pi^{\prime}(p+t)$, which is increasing in $t$. To rule this out, we must ensure that the contract curve in $C, t$ space is always downward sloping. A sufficient condition for this is for the supply function $\pi^{\prime}(p+t)$ not to be too concave or convex, as shown in the appendix.
} 
the government achieves with the cap; substituting efficient transfer for inefficient subsidies, that is, loosening the cap only erodes that gain.

Since the subsidy is not inefficient at $t=0$, use of $t$ will create joint gains to the government and lobby, which provides lobby goods in exchange for a strictly positive level of $t$. Hence, the equilibrium value of the inefficient transfer is positive. It is crucial to note that when $t$ is strictly positive it is strictly less efficient than the original transfer despite it being a perfect substitute at $t=0$.

\subsection{Export subsidies}

Our result in proposition 2 applies to a broader set of policies than production subsidies, as the following corollary shows. In particular it is interesting to consider the implication of our result for trade policy, which is universally used to redistribute income towards particular factor owners even though it is inefficient relative to lump-sum transfers. As Rodrik (1995) points out in his review of trade policy the use of trade policies as a form of redistribution remains an important unanswered question in trade. One particularly important transfer policy for developed countries is export subsidies, particularly in agriculture. Our previous result applies directly to export subsidies under the following conditions. ${ }^{18}$

Corollary: If good $i$ is exported when $t=0$ and trading costs and import barriers on $i$ are zero then a production subsidy is equivalent to an export subsidy and therefore proposition 2 provides an explanation for the use of export subsidies as a form of redistribution.

The corollary follows simply from the fact that an export subsidy is exactly equivalent to a production subsidy under the conditions outlined. Since we have assumed this is a small country the domestic consumers can purchase the good in the world market at $p$ provided there are no international trading costs or barriers on $i$, so demand for $i$ remains unchanged under an export subsidy. This implies that any extra production due to the subsidy is exported, and thus the production and export subsidy are equivalent.

\footnotetext{
${ }^{18}$ The WTO prohibits export subsidies on non-agricultural products for developed countries. However, such subsidies are still used and are in fact the source of some of the most important disputes in the WTO. In late 1997 the EU brought a complaint against the US's Foreign sales corporation system which allows any US firm whose exports have at least $50 \%$ of US content to set up a shell company in a tax haven that "buys" and then exports the product. Up to $65 \%$ of its profits are tax free. In 2003 the WTO has ruled in favor of the EU allowing retaliatory measures of up to $\$ 4$ billion.
} 


\section{The Government's Optimal Redistribution Policy}

Thus far we have allowed the government to set optimal caps on policies to clarify how the bargaining effect works. Moreover, we considered a sole inefficient alternative (a production subsidy) to make clear it is used when $T$ is optimally capped. Now that we have established how restraining the use of certain types of policies can improve the government's bargaining position, we show how this argument can explain the government's choice of inefficient policies in more realistic cases.

We don't often observe governments using the most efficient form of transfers in dealing with SIG. This suggests that instead of choosing optimal caps on policies, governments often choose simply whether or not to use the efficient policy instead of a relatively inefficient one. We therefore ask: Will the government ever choose to forego the efficient transfer completely and instead simply use a less efficient transfer policy? There are two offsetting effects. On the one hand, the improvement in its bargaining position provides a motive for the government to choose an inefficient policy, since it can therefore capture more of the existing bargaining surplus. On the other, an inefficient policy implies a lower total bargaining surplus. If the government has most of the bargaining power anyway, the reduction in total surplus is the more important effect. Since the government already has most of the bargaining power, an improvement in the bargaining position is relatively unimportant, so the government will prefer the efficient policy. Conversely, if the government has sufficiently low bargaining power it is likely to gain from switching to an inefficient policy. A reduction in the overall size of the surplus resulting from a switch to an inefficient policy is relatively less important when the government is not obtaining much of it to begin with, so that the effect on government bargaining position is likely to be the dominant consideration.

\subsection{A general condition}

We now provide a general sufficient condition for a government to choose the relatively inefficient transfer policy. Although we refer to the policies as $T$ and $t$ the general condition is not restricted to the comparison of lump-sum transfers and production subsidies. The condition applies to any two given transfer policies that can be introduced in the context of our model and can be ranked relative to each other in terms of their efficiency. For example, we may be interested in comparing the lumpsum transfer to the production subsidy and the production subsidy to an import tariff. The condition we derive reflects the basic trade off between bargaining surplus and bargaining position described above. We also show that the general condition can be satisfied in the case of the production subsidy.

The timing of the game now entails an initial stage when the government chooses whether to 
use $T$ or $t$ as a transfer. Once a policy is chosen the government can't set any type of cap on it. After choosing which policy will be used the government bargains with the lobby. A government with bargaining power $\gamma$ chooses the inefficient policy if

$$
G\left(T=0, t^{N t}(\gamma), C^{N t}(\gamma)\right)>G\left(T=T^{N}(\gamma), t=0, C^{N}\right)
$$

Figure 5 shows that this condition may hold in the case of lump-sum transfers and some inefficient policy. The line $g^{m} v^{m}$ represents the Pareto frontier when $T$ is used. The curve $g^{m t} v^{m t}$ represents the frontier when an inefficient policy $t$ is used, which is interior to $g^{m} v^{m}$ because $t$ is inefficient. Intuitively, (12) is likely to hold for low $\gamma$, that is for low government bargaining power. It cannot hold for $\gamma=0$, since the government then receives its reservation utility, which is identical for $T$ and $t$. Therefore, if at $\gamma=0$ the government's marginal gain from an increase in $\gamma$ is higher under $t$ then (12) is satisfied for sufficiently low $\gamma$ since the government's maximized objective is continuous in $\gamma$. So a sufficient condition for a government to choose the inefficient policy when $\gamma$ is sufficiently low is

$$
\lim _{\gamma \rightarrow 0} \frac{\partial}{\partial \gamma} G\left(0, t^{N t}(\gamma), C^{N t}(\gamma)\right)>\lim _{\gamma \rightarrow 0} \frac{\partial}{\partial \gamma} G\left(T^{N}(\gamma), 0, C^{N}\right)
$$

It is also clear from Figure 5 that, for sufficiently large $\gamma$, the government always chooses $T$ since at $\gamma=1$ we have $g^{m}>g^{m t}$. We represent this in Figure 6 where we plot the government's maximized utility as a function of its bargaining power. Therefore, if (13) holds, there must exist at least one critical point $\gamma^{*} \in(0,1)$ such that the government is indifferent between the transfer policies used. ${ }^{19}$

$$
G\left(0, t^{N t}\left(\gamma^{*}\right), C^{N t}\left(\gamma^{*}\right)\right)=G\left(T^{N}\left(\gamma^{*}\right), 0, C^{N}\right)
$$

When (14) has multiple solutions, we take as $\gamma^{*}$ the minimum $\gamma$ satisfying it.

Before stating the proposition it is useful to define the Pareto frontier when a given policy $x=T$ or $t$ is used as $V^{x}-v^{0}=\Omega^{x}\left(G^{x}-g^{0}\right)$. For example, when only lump-sum transfers are used, $\Omega^{T}(\cdot)$ is $-\frac{1-\beta}{a \beta}\left(G-g^{0}\right)$. Note that $\Omega^{x}(0)=0$ and $\Omega^{\prime} x<0$. The slope of the Pareto frontier in Figure 5 is $1 / \Omega^{\prime}$. We may then show:

\section{Proposition 3 :}

a. Given a discrete choice of the transfer policy to use in bargaining with a lobby the government

\footnotetext{
${ }^{19}$ Given that $g^{N}$ is linear in $\gamma$, as seen in (10), we could check that when $\gamma^{*}$ exists it is unique by confirming whether $g^{N t}$ is strictly concave for the particular policy $t$ considered. In general if there are multiple $\gamma^{*}$ we can simply take the minimum of them when (13) holds to show that when $\gamma \in\left(0, \gamma^{*}\right)$ the government chooses $t$.
} 
chooses a relatively more inefficient transfer, $t$, instead of $T$ if:

i. $\lim _{\gamma \rightarrow 0}\left(1 / \Omega^{\prime t}\right) /\left(1 / \Omega^{\prime T}\right)>\lim _{\gamma \rightarrow 0} \Omega^{T} / \Omega^{t}$ and

ii. $\gamma \in\left(0, \gamma^{*}\right)$

b. Moreover, there exists $a \bar{\gamma} \in\left[\gamma^{*}, 1\right)$ s.t. the government always chooses $T$ when $\gamma \in(\bar{\gamma}, 1]$.

\section{Proof: See Appendix}

The proposition states that the government chooses $t$ for sufficiently low $\gamma$ if the fall in the surplus from switching to the inefficient policy is small, that is, if $\lim _{\gamma \rightarrow 0} \Omega^{T} / \Omega^{t}$ is small, relative to the improvement in the government's bargaining position, reflected by the increase in the steepness of the Pareto frontier from using $t$, that is, by $\lim _{\gamma \rightarrow 0}\left(1 / \Omega^{\prime t}\right) /\left(1 / \Omega^{\prime T}\right)$. The intuition is exactly as explained above. To better understand the sufficient condition in part (a) of the proposition, consider Figure 5. For the drawn Pareto frontiers we can find $\gamma^{*}$ by simply taking a line through $g^{m}$ tangent to the Pareto frontier for $t$. Using a reasoning similar to that in the proof of proposition 1 the solution when $t$ is used and the auxiliary line is tangent to the Pareto frontier for $t$ entails the same utility for the government as does the solution when $T$ is used. Thus, the auxiliary lines through $g^{m}$ that intersect the frontier for $t$ when $\gamma<\gamma^{*}$ must be less steep than the frontier, when it is strictly concave. So the solution when $t$ is used involves higher $g$ for $\gamma \in\left(0, \gamma^{*}\right)$. Part b of the proposition states that if the government has most of the bargaining power, so that it obtains most of the surplus, it prefers the policy that maximizes the surplus, i.e., $T$.

We further note that in general there may be no $\gamma^{*}>0$ that satisfies (14) so the condition must be checked for specific pairs of policies. We now show when the general condition holds for the case of lump-sum transfers and production subsidies which, as pointed out in a previous corollary, will also apply to export subsidies in this small open economy.

\subsection{Production subsidies versus lump-sum transfers}

In the case of production subsidies we have $\lim _{\gamma \rightarrow 0}\left(1 / \Omega^{\prime t}\right) /\left(1 / \Omega^{\prime T}\right)=\Psi^{\prime}\left(C^{N t}\right) / \Psi^{\prime}\left(C^{N}\right)$, where $\Psi^{\prime}\left(C^{N}\right)$ is constant as shown in (7). Therefore, for a given level of $C$, a more concave $\Psi(\cdot)$ implies a steeper Pareto frontier only for the case of inefficient transfers. As we have argued, a steeper Pareto frontier implies that the government improves its bargaining position by switching to the inefficient policy. However, as we consider alternative $\Psi(\cdot)$ functions, the equilibrium levels of $C^{m t}, t$ and $T$ at $\gamma=0$ also change. This could potentially imply that $\Psi^{\prime}\left(C^{N t}\right)$ is lower when $\Psi$ is more concave and/or that the right hand side of (13) increases, such that a more concave $\Psi(\cdot)$ may not be sufficient. A simple 
example will suffice to show that, despite any equilibrium responses of the policies, a more concave $\Psi(\cdot)$ has the effect described and that (13) can be easily satisfied in the case of production subsidies.

As we show in detail in the appendix in the case of lump-sum transfers and production subsidies the model yields

$$
\begin{aligned}
\lim _{\gamma \rightarrow 0}-\frac{\Omega^{T}}{\Omega^{\prime T}} & =\Psi\left(C^{N}\right)-\frac{a \beta}{1-\beta} C^{N} \\
\lim _{\gamma \rightarrow 0}-\frac{\Omega^{t}}{\Omega^{\prime t}} & =\lim _{\gamma \rightarrow 0}\left[\frac{a\left(\beta \pi^{\prime}\left(p+t^{N}\right)+t^{N} \pi^{\prime \prime}\left(p+t^{N}\right)\right)}{(1-\beta) \pi^{\prime}\left(p+t^{N}\right)}\left(\pi\left(p+t^{N}\right)-\pi(p)-C^{m t}\right)\right]
\end{aligned}
$$

where $C^{m t}$ is the minimum level of the good provided by the lobby to maintain the government at the reservation utility. Using the definition of $G$ we can write $C^{m t}$ as a function of $t^{N}$. Thus we need only parametrize the production and $\Psi(\cdot)$ functions. We assume $\Psi(C) \equiv C^{\psi}$ and $\psi \in(0,1)$, which satisfies the conditions previously assumed for $\Psi(\cdot)$. Production is Cobb-Douglas with capital share of 0.5. In the appendix we solve explicitly for the equilibrium production subsidy and evaluate the slopes at the parameter values listed below. The simulation confirms that when $\Psi(\cdot)$ is sufficiently concave the slope condition is satisfied and the government chooses $t$ if $\gamma \in\left(0, \gamma^{*}\right)$ as reported in the table below.

\begin{tabular}{cccc} 
& \multicolumn{3}{c}{$\lim _{\gamma \rightarrow 0}-\frac{\Omega^{x}}{\Omega^{x \prime}}$} \\
\hline$\psi$ & $x=t$ & & $x=T$ \\
\hline $1 / 2$ & 0.46 & $<$ & 0.75 \\
$1 / 4$ & 0.82 & $>$ & 0.68 \\
\hline Parameters: $a=p=k=1, \beta=0.25, \alpha=0.5, \gamma=0$ \\
Functions: $\Psi=C^{\psi} ; q=k^{.5} .5$
\end{tabular}

Table 1: Simulation result for the choice of lump-sum versus production subsidies

\subsection{Choice over multiple redistribution policies}

Proposition 3 can be used to compare policies other than the lump-sum transfer and production subsidy provided that we can rank them in terms of efficiency. This implies that we can use the condition to determine the government's optimal redistribution policy towards an interest group as a function of its bargaining power when facing that group. For example we can compare the production subsidy to the lump-sum transfer and subsequently, if we find the production subsidy is chosen for $\gamma \in\left(0, \gamma^{*}\right)$, compare the production subsidy with a tariff. For any set of redistributive policies that can be efficiency ranked, we could find the range of $\gamma$ for which each of them is the government's most preferred policy. Of course, there will be policies which are not the government's first choice for any value of $\gamma$. This could be represented analogously to Figure 6 . That is we could represent for 
each policy $x$ how $g^{N x}(\gamma)-g^{0}$ increases as a function of $\gamma$. The outer envelope over all the available policies would then define the optimal redistribution policy for the government at each level of $\gamma$.

Whether a government will use only one or several policies to redistribute income to a SIG depends on whether or not the policies can be capped at positive levels. If "interior" caps are not possible, then our bargaining model indicates that only one type of policy will be used - though, as we have just shown, not necessarily the most efficient one. A key implication of proposition 3 is that when the government cannot set the optimal cap on efficient transfers it might find it optimal to forego their use entirely, so that we would see only an inefficient policy being used.

When it is possible to put binding caps on the use of some policies, then several redistributive policies might be used at the same time. The government would cap the relatively more efficient policy at some positive level. If the less efficient policy cannot be prohibited, these two policies would coexist. We do sometimes observe two relatively inefficient policies used simultaneously, for example, production subsidies and tariffs, or tariffs and a protectionist product standard. Our model can explain how this can be observed in a political equilibrium in which the government has low bargaining power with respect to SIG (so the use of inefficient policies would be prevalent) and can only partially limit the use of some redistributive policies.

Proposition 3 also contains an interesting prediction that is potentially testable. The use of inefficient policies should be more prevalent when the government has low bargaining power. The opposite is true if $\gamma$ is high. This can be tested across countries, states or within a country if we can rank a government's bargaining power versus different lobbies. The theory mapping alternating offers to Nash bargaining provides some guidance for what might determine $\gamma$, which could be used for this ranking.

\section{Equilibrium Redistribution Policy}

Up to now, we have assumed that the government can unilaterally choose the cap on the efficient policy, or, in the binary case, the redistribution policy itself. In such a case, the equilibrium redistribution policy or set of policies is simply the one that is optimal from the government's perspective, as given in propositions 3 and 2. In this section we consider two simple extensions of the model that incorporate the "demand" for policy by those affected. First, we allow lobbies to bargain with the government over the policy to be used in the first stage. Second, we allow for elections to choose a policymaker, where all candidates value both welfare and lobby goods as before, but where they differ in the value that they place on social welfare. We show that our results are generally robust to 
these extensions.

\subsection{Bargaining over the equilibrium redistribution policy}

Thus far we have assumed that the government makes the first stage choice of a cap or policy to maximize its welfare or (as in some of our examples) that the policy or cap is exogenously specified. These assumptions seem at least as reasonable as assuming that lobbies have full control over the policy choice (as in the menu-auction approach, which derives a gain from the use of inefficient policies for lobbies that it argues explains their use in equilibrium). In practice the most reasonable case is one where the government cannot fully commit to a cap or the use of a single policy, so that both the government and lobby influence the choice of the policy. We now discuss this case in greater detail and show that even if we allow the lobby to bargain over the redistribution policy with the government in the first stage, the inefficient policy may still be used in equilibrium.

There are numerous ways in which we could model the government interaction with the lobby in the first stage. Our main objective here is to eliminate the asymmetry in the previous sections that arises from allowing the government to make a take-it-or-leave-it offer on the cap or policy choice. We therefore maintain the rest of the structure of the model and simply allow the lobby and the government to bargain over the policy (cap) in the first stage. To remain consistent with the original setup we do not allow any other instruments or transfers to be bargained over in that initial stage. Below we will provide a valid reason why each individual lobby will be unwilling to make any transfers to the government in the first stage for a particular policy to be available (or not capped) in the second stage. For now we simply assume this.

Consider first the case of a cap on efficient transfers when inefficient policies are also available, as discussed in section 4. As shown in proposition 2 when the government can choose caps it sets a binding cap on $T$ provided neither party has all the bargaining power in the second stage, when the level of the policies are determined. If instead we allowed lobbies to set the cap, they would choose a non-binding cap. Each of these outcomes can be seen as the extreme when each side has all the bargaining power in the first stage. Suppose now that the government's bargaining power in the first stage is $\gamma_{1}$. Note that in general we would expect $\gamma_{1}$ to differ from $\gamma$, the bargaining power once the policy has been decided on. The reason for this is that the parties are bargaining over different things in the two stages: the choice of transfer policy or cap in the first stage as opposed to the level of the policy and transfers in the second. ${ }^{20}$

\footnotetext{
${ }^{20}$ Even a narrow interpretation of $\gamma$ when Nash bargaining represents alternating offers suggests that the risk of breakdown may be different at the different stages.
} 
The threat point in the first stage is as before $g_{0}, v_{0}$, the no bargaining outcome. In the special case where $\gamma_{1}=\gamma$ allowing for bargaining in the first stage leads to the unconstrained Nash solution and therefore only the efficient policy is used. To see why, note that Nash bargaining in the first stage implies that the cap is jointly efficient. When the bargaining power is identical in the two stages, the Nash product being maximized in the first stage is the same as in the second stage. Since the Pareto frontier in the first stage includes the point with a non-binding cap and this has the highest joint surplus, it is the solution. The same is true if government bargaining power is lower in the first stage than in the second, i.e. if $\gamma_{1}<\gamma$. This is illustrated in Figure 7, which shows the Pareto frontier in the first stage as the non-dashed curve through $N$, when $T^{c}=T^{N}, N^{c^{\prime}}, T^{c}=T^{N c}$, and $g_{0}, T^{c}=0$.

In contrast, when the government has more bargaining power in the first stage, i.e. $\gamma_{1}>\gamma$, a binding cap results and the inefficient policy is used in equilibrium if and only if neither side has all the bargaining power in the second stage. Such a solution is illustrated by $N^{b}$ in figure 7. The intuition for this result is that, when $\gamma_{1}>\gamma$, choosing $T^{c}$ to maximize joint utility in the first stage, $\left(G\left(C^{N c}\left(T^{c}\right), T^{N c}\left(T^{c}\right), t^{N c}\left(T^{c}\right)\right)-g_{0}\right)^{\gamma_{1}}\left(V\left(C^{N c}\left(T^{c}\right), T^{N c}\left(T^{c}\right), t^{N c}\left(T^{c}\right)-v_{0}\right)^{1-\gamma_{1}}\right.$, requires a higher utility for the government than the unconstrained Nash level, which maximizes $(G(C, T, t))-$ $\left.g_{0}\right)^{\gamma}\left(V\left(C, T, t-v_{0}\right)^{1-\gamma}\right.$. This argument relies on the fact that as $T^{c} \rightarrow T^{N}$ the slope of the constrained frontier becomes identical to that of the unconstrained one, as previously shown. It seems plausible that $\gamma_{1}>\gamma$ since in the first stage the only instrument that is bargained over is under the control of the government-a particular type of legislation. So, given this condition is satisfied, allowing for lobbies to bargain over the cap on $T$ does not eliminate the result that the equilibrium redistribution policy is the inefficient one.

Things are more complex with binary choice of policies, since the result of first-stage bargaining cannot be a policy somewhere between the policy preferred by the government and that preferred by the lobby. One way of representing the possible outcome of bargaining when choices are discrete in the first stage is as follows. With some probability $\rho$ the government chooses the policy and with probability $1-\rho$, the lobby chooses the policy. Previously we assumed $\rho=1$ and showed that under the conditions in proposition 3 the equilibrium policy is the inefficient one. More generally, if whenever the government has some bargaining power it has a non-zero probability of being able to choose the policy then we still observe $t$ as the equilibrium redistribution policy with probability $\rho$ if the conditions in proposition 3 hold. ${ }^{21}$

We have allowed bargaining only over the choice of policy or cap in the initial stage. But if the

\footnotetext{
${ }^{21}$ If one made the further reasonable assumption that the probability $\rho$ that the government chooses the policy is increasing in $\gamma$, then the probability of the policy being inefficient (when $\gamma<\gamma^{*}$ ) is increasing in $\gamma$.
} 
inefficient policy is chosen in the first stage, there will potentially be unexplored gains from bargaining. One may therefore ask why any given lobby $i$ would not offer a side-payment to the government, for example, some of the lobby good, in exchange for the government using the efficient policy towards it, leaving both sides at least as well off as under the inefficient policy. One answer is that each individual lobby may not find it optimal to do this due to a free riding problem across lobbies. Suppose that whenever the government chooses a more efficient policy in place of another relatively inefficient one, it does so through an agreement or legislation that necessarily applies to several sectors, so that if the government agrees to switch redistribution policies for one lobby it may need to do so for all. Hence, there is a basic collective action problem. In the absence of coordination across lobbies and if no individual lobby can make itself better off when it compensates the government for the loss of switching to the efficient policy for all lobbies we should not expect side payments used in the first stage. This can justify the type of bargaining we model above that can predict an inefficient equilibrium redistribution policy even if we allow the lobbies to influence it. ${ }^{22}$

\subsection{Majority support for inefficient redistribution policies}

Suppose now that the choice of redistribution policy is subject to a referendum or, alternatively, that there are several politicians who differ only in their known valuation of social welfare, $a$. We assume that $a$ may be large but not infinite, that is, all politicians value lobby goods. The question we ask is the following: Will the inefficient policy ever be voted for or, alternatively, will a politician that implements the inefficient policy ever be elected? We consider the second alternative, voting over politicians with known characteristics.

The electoral setup is simple. Voting is costless (and sincere in the two candidate election), with a voter's choices depending only on the known (and immutable) characteristics of the candidates. ${ }^{23}$ A politician $P_{x}\left(a_{x}, \gamma_{x}\right)$, whose type is known by all, if elected chooses the policy that maximizes his welfare in bargaining with the organized lobbies.

To study election outcomes, we must derive voter preferences over the politicians. There are three groups of voters with potentially different voting preferences: organized owners of capital $i \in L$, unorganized owners, $j$, and workers. As will become clear, the latter two groups have similar

\footnotetext{
${ }^{22}$ Alternatively if we allowed the government to make exceptions it may still be possible for the inefficient policy to emerge in equilibrium if those exceptions are sufficiently costly for the government to negotiate once the rule has been decided.

${ }^{23}$ Since the voters in our model are rational and have full information they are not "impressionable". That is they cannot be persuaded to vote for someone by campaigning and so contributions are not useful in electing politicians. This further reinforces our interpretation of $C_{i}$ as lobby goods valued by a politician in office, independently of elections, rather than as contributions.
} 
preferences over the politicians considered. Moreover, for a given redistribution policy the latter two groups prefer a politician that will deliver higher social welfare.

The qualitative outcome in the case with optimal caps is trivial. All politicians that value both social welfare and $C$ favor caps as shown in propositions 1 and 2, which implies that any elected politician will set a cap and $t$ will be used in equilibrium. Therefore we focus on the less trivial binary choice case of section 5 .

If elected, a politician of type $P_{x}\left(a_{x}, \gamma_{x}\right)$ will choose $t$ or $T$ depending on which maximizes his objective $G(a,$.$) . If \gamma<\gamma^{*}(a)$ for a given politician (and condition (a)(ii) in proposition 3 holds), he chooses $t$. But $\gamma^{*}$ depends on $a$, as is clear from (14). Thus, two politicians with similar $\gamma$ may have different preferences over the transfer policy. Given that this is a full information model the voters know the politician's type and therefore which policy he will implement after he is elected. Therefore they vote not on the basis of $a$ alone but on the basis of the welfare outcome under alternative politicians, which again depends on his optimal redistribution policy.

We begin by characterizing the preferences of the three groups in a special but important case, which will be important for characterizing election outcomes.

Lemma 2: Under a politician $P_{x}\left(a_{x}, \gamma=\gamma^{*}\left(a_{x}\right)\right)$, both unorganized capital owners and workers prefer the inefficient policy $t$ to $T$, while organized capital owners prefer $T$ to $t$. Hence, under politician $P_{x}\left(a_{x}, \gamma=\gamma^{*}\left(a_{x}\right)\right)$, a majority prefers $t$ to $T$ if and only if workers and unorganized capital owners are in the majority, that is, iff $\sum_{i \in L} \alpha_{i}<0.5$.

\section{Proof: See appendix.}

The lemma states that when a politician who is indifferent between $t$ and $T$ is in power, then a majority prefers the inefficient policy if and only if organized capital owners are the minority. Recall that we assume concentrated ownership of capital in each organized sector, so the condition in the lemma further requires that organized capital owners are a minority of the voting population, which is reasonable.

The intuition for the result is simple. The inefficient policy reduces the total bargaining surplus between the politician and lobbies is reduced (see Lemma 1). Therefore the lobby is worse off with $t$. When $t$ rather than $T$ is used, equilibrium $C$ is lower, so that $\Psi(C)$ is lower as well. Since $G=a W+\Psi(C)$, if the government is indifferent between $t$ and $T$, it must be that social welfare $W$ under $t$ is higher. Since social welfare is the aggregation of welfare for workers and the unorganized and organized capital owners, if organized capital owners are worse off under $t$ (as just argued) the welfare of workers and unorganized capital owners must be higher. Moreover, it is simple to show (see 
the proof) that the latter two groups have the same preferences over the choice of transfer policies and thus if they are better off on aggregate, then each of these two subgroups is better off.

On the basis of Lemma 2, we can consider election (and hence policy) outcomes when voters choose between candidates with different $a$, that is, weight on social welfare, but the same bargaining power $\gamma$ towards lobbies. If we consider a contest between a candidate whose $a$ makes him indifferent between the two policies and one with a different $a$ (but the same $\gamma$ ), the policy choice of the latter will depend on how $\gamma^{*}$ changes with $a$. If $d \gamma^{*} / d a>0$, then over some range of $a$ and $\gamma$ politicians who care more about social welfare are more likely to choose inefficient policies. If $d \gamma^{*} / d a<0$, then politicians who care less about social welfare are more likely to choose inefficient policies. Although the first case, $d \gamma^{*} / d a>0$, appears counterintuitive it may be possible, so that we must consider both cases. To understand why, recall from Lemma 2 that at $\gamma^{*}$, social welfare $W$ is higher under $t$ than $T$. Since the direct effect of an increase in $a$ for the politician at given policy levels is $W$, the utility of a politician $P_{x}\left(a_{x}, \gamma=\gamma^{*}\left(a_{x}\right)\right)$ increases by more under $t$, so at higher $a$ he would choose $t$. Hence, the direct effect implies a higher $\gamma^{*}$, raising the possibility that politicians with higher $a$ are more likely to choose inefficient policies, at least over some range. However, higher $a$ also changes the equilibrium level of the policies, lowering transfers and $C$. The net effect of this second channel under $t$ relative to $T$ is ambiguous and will generally depend on the other parameters of the model and the functional form of $\pi$ and $\Psi .^{24}$

The timing is now as follows. In the first stage there is an election to choose the policymaker. All politicians share $\gamma$ but some politicians differ in their $a$, where $a$ is bounded, so no politician is a social welfare maximizer. Once the politician is elected he bargains with the lobby over the value of the transfer policy voted and $C$. Thus this last stage is as before in the binary choice section. We may then show that rational voters may vote for a candidate who is known to implement the inefficient policy over one who would implement the efficient policy.

\section{Proposition 4 :}

When $d \gamma^{*} / d a>0$ a politician $P_{t}\left(a_{t}>a, \gamma=\gamma^{*}(a)\right)$ implements the inefficient policy. Moreover, if $\sum_{i \in L} \alpha_{i}<0.5$ then $P_{t}$ wins a majority vote against all politicians with the same bargaining power

\footnotetext{
${ }^{24}$ To derive $d \gamma^{*} / d a$ we must trace out the intersection of the government's utility in figure 6. Formally we use (14) to obtain $d \gamma^{*} / d a=-\left(d \hat{G}^{t} / d a-d \hat{G}^{T} / d a\right) /\left(d \hat{G}^{t} / d \gamma-d \hat{G}^{T} / d \gamma\right)$. When $\gamma^{*}$ exists and (13) holds we know that the denominator is negative at $\gamma^{*}$, as is clear from figure 6 . Therefore

$$
\begin{aligned}
\operatorname{sign}\left(d \gamma^{*} / d a\right) & =\operatorname{sign}\left(d \hat{G}^{t} / d a-d \hat{G}^{T} / d a\right) \\
& =\operatorname{sign}\left(G_{a}(t)-G_{a}(T)+G_{t} t_{a}-G_{T} T_{a}+\left[G_{C} C_{a}^{N t}\right]_{C=C^{N t}}-\left[G_{C} C_{a}^{N}\right]_{C=C^{N}}\right)
\end{aligned}
$$
}


who implement $T, P_{T}\left(a_{T}<a, \gamma\right)$.

When $d \gamma^{*} / d a<0$ a politician $P_{t}\left(a_{t}<a, \gamma=\gamma^{*}(a)\right)$ implements the inefficient policy. Moreover if $\sum_{i \in L} \alpha_{i}<0.5$ then $P_{t}$ wins a majority vote against all politicians with the same bargaining power who implement $T, P_{T}\left(a_{T}>a, \gamma\right)$, unless $P_{T}$ cares sufficiently more about social welfare than $P_{t}$, that is unless $a_{T}-a_{t}$ is sufficiently large.

\section{Proof: See Appendix}

The proposition provides the conditions under which a politician preferring the inefficient policy may win an election against one preferring the efficient one. The first case states that if the organized lobbies are not the majority of the voters and $d \gamma^{*} / d a>0$, then a politician who implements $t$ cannot be beaten by any politician with the same bargaining power $\gamma$ and lower $a$, including those who find $T$ optimal. Workers and unorganized capital owners prefer $P_{t}$ both because he has a higher $a$ then any politician that prefers $T$ and because he chooses $t$. Politicians who place a higher weight on social welfare are the ones that choose inefficient policies and they are also the ones elected.

The second case in the proposition says that a politician that places lower value on social welfare will be elected by the workers and unorganized capital owners provided that he chooses $t$ and the alternative candidate with the same $\gamma$ has a sufficiently high $a$ to prefer $T$ but not high enough to offset the extra social cost from doing so. ${ }^{25}$ In this case a higher value of $a$ for a candidate who is indifferent between $t$ and $T$ works against him because it changes his optimal redistribution policy. This switch to $T$ implies a discrete fall in social welfare which is more than enough to offset the marginal increase in welfare from the higher $a$. Note that in this second case fully informed, rational voters may choose the candidate with a lower weight on social welfare. They do so precisely because he chooses the inefficient policy implying higher equilibrium voter welfare.

In a way the result in proposition 4 stands in sharp contrast to the disguised transfer theory as formalized for example by Coate and Morris (1995). They require asymmetric and imperfect voter information about the effects of policies and the politician type to show that we may obtain a voting equilibrium where inefficient redistribution policies are used. The proposition above shows that this sort of result, in which elected politicians pursue inefficient redistribution policies, is perfectly consistent with rational, forward-looking voters who are fully informed and vote solely on the basis of what type of redistribution policy will be used in equilibrium.

\footnotetext{
${ }^{25}$ Naturally if there exist candidates with sufficiently high $a(<\infty)$ that can enter the race, as in some citizen-candidate models, and $d \gamma^{*} / d a<0$, then they would choose $T$ and be elected. Our point is that if we consider two given candidates, the one with lower $a$ who chooses $t$ over $T$ may be elected for exactly that reason.
} 


\section{Conclusion}

Why do governments use inefficient policies to make transfers to SIG? This question has long puzzled researchers in public economics, political economy and trade policy. We present an argument that relies on two features of the interaction between the government and SIG that we think are general, pervasive, and important. First, this interaction can be characterized as one where the two parties

bargain over what they have to offer to each other. Second, the government has some ability to commit to certain limits on the types and/or levels of the policies that it will later bargain over.

In such a world, a key consideration is the bargaining position of the government relative to the lobbies. The government will benefit if it can commit itself to offer lower transfers for any given amount of lobby goods that the SIG provides. As we demonstrated, this commitment increases the welfare of the government because it improves its bargaining position. However, if the government caps or foregoes the use of one instrument, lobbies will find other, generally less efficient ways to bargain with the government. Hence, equilibrium redistribution is characterized by the use of inefficient instruments. If such instruments serve no social purpose, the government will also want to prohibit their use, but it will certainly find it impossible to eliminate every conceivable transfer to SIG. If the inefficient transfer has a social value at some point in time, such as a production subsidy to correct an externality, the government will not find it optimal to prohibit its use. However, it is then impossible to effectively forbid its use as a redistributive device. Focussing on the case in which the inefficient instrument is known to have no social purpose makes clear that the use of inefficient ways of transferring income to SIG is completely independent of any motive related to lack of transparency and imperfect information.

When the government has the ability to choose caps optimally, efficient and inefficient transfers will both be used (or, more generally, several types of policies may be used simultaneously). In practice, the government may not be able to choose interior values for caps and may thus face a binary problem of choosing between efficient and inefficient transfer policies. The same arguments apply, so that a government with low bargaining power may choose to forego the use of efficient transfers and use only inefficient ones to improve its bargaining position. Hence, our bargaining approach can explain why inefficient transfers are used instead of efficient ones. Even when the government cannot fully commit to a cap or the use of a single policy, so that the government and lobby bargain over the redistribution policy, the inefficient policy may still be used in equilibrium.

In an electoral framework we found that rational, fully informed voters may prefer the candidate who chooses the inefficient policy to one who chooses the efficient one. For the same reason they may 
prefer the candidate who puts a lower weight on social welfare because they know the improvement in the government's bargaining position relative to the SIGs that this implies will lead to higher social welfare. These voter preferences do not reflect imperfect information about candidates or the effect of transfers, as in many models. Moreover, these results suggest the importance of looking at the interaction of voting models with lobbying models, but in a framework where neither government nor lobbies have all the bargaining power as in the approach to SIGs put forward here.

The model also provides a rationale for commitment via international agreements other than as a solution to time inconsistency problems, as is often suggested. In our approach the gain to the government from self-restraint (which might be achieved via international agreements) is explained by the improvement in its bargaining position relative to the lobby.

We chose a specific application to demonstrate a general mechanism that appears to be commonly used in practice by governments: restraining the amount they can offer in a subsequent bargain. A similar rationale can potentially explain the choice of inefficient transfer policies other than production and export subsidies. As pointed out above, it can also apply in different political economy settings provided that the key bargaining elements are present.

Finally, our results highlight an important methodological issue about the interaction of governments and SIG. Models that assign all the bargaining power to either party will fail to explain interesting outcomes, which suggests the high value to investigating alternative approaches to the interaction between governments and SIG. That is the more general aim of our line of research. 


\section{References}

Acemoglu, D. and J. Robinson (2001), "Inefficient Redistribution," American Political Science Review 95, 649-61.

Baron, D. (1991), "Majoritarian Incentives, Pork Barrel Programs, and Procedural Control," American Journal of Political Science 35, 57-90.

Becker, G. (1983), "A Theory of Competition among Interest Groups for Political Influence," Quarterly Journal of Economics 98, 371-400.

Becker, G. and C. Mulligan (1998), "Deadweight Costs and the Size of Government," NBER working paper 6789.

Binmore, K., A. Rubinstein, and A. Wolinsky (1986), "The Nash Bargaining Solution in Economic Modelling," Rand Journal of Economics 17, 176-88.

Coate, S. and S. Morris (1995), "On the Form of transfers to Special Interests," Journal of Political Economy 103, 1210-35.

Dixit, A., G. M. Grossman, and E. Helpman, (1997) "Common Agency and Coordination: General Theory and Application to Government Policy Making," Journal of Political Economy 105(4), 75269.

Dixit, A. and J. Londregan (1995), "Redistributional Politics and Economic Efficiency," American Political Science Review 89, 856-66.

Drazen, A. (2002). "Conditionality and Ownership in IMF Lending: A Political Economy Approach," IMF Staff Papers 49 (Special Issue), 36-67.

Fiorina, M. (1981), "Universalism, Reciprocity, and Distributive Policymaking in Majority Rule Institutions," in J. Crecine, ed., Research in Public Policy Analysis and Management, vol. 1, Greenwich, CT: JAI Press.

Grossman, G. M. and E. Helpman (1994), "Protection for Sale," American Economic Review 84, 833-50.

Maggi,G and A. Rodriguez-Clare (1998), "The Value of Trade Agreements in the Presence of Political Pressures," Journal of Political Economy 106(3), 574-601.

Rodrik, D. (1986), "Taxes, Subsidies, and Welfare with Endogenous Policy," Journal of International Economics 21, 285-99.

(1995), "Political Economy of Trade Policy," in Gene M. Grossman and Kenneth Rogoff, eds., Handbook of International Economics, Vol. 3. Amsterdam: North-Holland, 1457-94.

Shepsle, K. and B. Weingast, (1981), "Political Preferences for the Pork Barrel: A Generalization," American Journal of Political Science 25, 96-112.

Staiger, R.W. and G. Tabellini (1987), "Discretionary Trade Policy and Excessive Protection" American Economic Review 77, 823-37.

Tullock, G. (1983), Economics of Income Redistribution, Boston MA: Kluwer-Nijhoff.

Vlasenko, P. (2003), "Privatization and New Entry in Transition Economies," Doctoral Dissertation, University of Maryland.

Weingast, B., K. Shepsle, and C. Johnsen (1981), " The Political Economy of Benefits and Costs: A Neoclassical Approach to Distributive Politics," Journal of Political Economy 89, 642-64.

Westcott, P., C. E.Young, and J. M. Price (2002) "The 2002 Farm Act: Provisions and Implications for Commodity Markets", Agriculture Information Bulletin no. 778.

Wilson, J.(1990), "Are Efficiency Improvements in Government Transfer Policies Self-Defeating in Political Equilibrium," Economics and Politics 2, 241-58. 


\section{APPENDICES}

\section{A Formal Definition of the Political Equilibrium}

In this appendix we provide a formal definition of the political equilibrium described in section 4 when there are $i=1, \ldots, N$ SIG.

The set $\left(\left\{\hat{T}_{i}^{c}\right\},\left\{\hat{T}_{i}\right\},\left\{\hat{t}_{i}\right\},\left\{\hat{C}_{i}\right\}\right)$ for $i=1, \ldots N$ forms a subgame perfect Nash equilibrium of this game if and only if

1. Caps:

$$
\hat{T}_{i}^{c} \equiv \arg \max _{T_{i}^{c}} G\left(\hat{C}_{i}\left(T_{i}^{c}\right), \hat{T}_{i}\left(T_{i}^{c}\right), \hat{t}_{i}\left(T_{i}^{c}\right)\right) \text { all } i
$$

2. Levels of $T, t$ and $C$

$$
\left(\hat{C}_{i}, \hat{T}_{i}, \hat{t}_{i}\right) \equiv \arg \max _{\left(G, V_{i}\right) \in \Omega}\left(G-g^{0}\right)^{\gamma}\left(V_{i}-v_{i}^{0}\right)^{1-\gamma}
$$

where $\Omega \equiv\left\{\left(G, V_{i}\right) \in P^{e}: G \geq G^{0}, V_{i} \geq V_{i}^{0}\right\} \quad$ [Pareto frontier]

and

i. $g^{0} \equiv \max _{T_{i} \geq 0, t_{i} \geq 0}\left\{G\left(C_{i}, T_{i}\left(T_{i}^{c}\right), t_{i}\left(T_{i}^{c}\right)\right)\right\} \quad$ [Threat point for government]

ii. $v_{i}^{0} \equiv \max _{C_{i} \geq 0}\left\{V_{0}\left(C_{i}, T_{i}, t_{i}\right\} \quad\right.$ [Threat point for lobby]

iii. $\left(G, V_{i}\right) \in P^{e}$ iff

$\left(G, V_{i}\right) \in P$

$\nexists\left(G, V_{i}\right)$ s.t. $T_{i} \in\left[0, \hat{T}_{i}^{c}\right]$;

[Set of feasible utilities for the problem] and

a. $G\left(C_{i}, T_{i}, t_{i}\right) \geq G\left(\hat{C}_{i}, \hat{T}_{i}, \hat{t}_{i}\right)$ and $V_{i}\left(C_{i}, T_{i}, t_{i}\right)>V_{i}\left(\hat{C}_{i}, \hat{T}_{i}, \hat{t}_{i}\right)$ or

b. $G\left(C_{i}, T_{i}, t_{i}\right)>G\left(\hat{C}_{i}, \hat{T}_{i}, \hat{t}_{i}\right)$ and $V_{i}\left(C_{i}, T_{i}, t_{i}\right) \geq V_{i}\left(\hat{C}_{i}, \hat{T}_{i}, \hat{t}_{i}\right)$.

\section{B Production subsidies as efficient transfer policies}

Lemma 1: A production subsidy $t$ is an inefficient transfer policy relative to $T$ iff no production externality is present.

Proof:

Sufficiency: Consider the case where no externality is present, so that the economically optimal level of $t$ is $t^{*}=0$. Deriving a contract curve in $T-t$ space for any given level of $C$, the definition requires that such a curve contain no points such that $t>0$. For this to true, it must be the case that $t>0$ implies no gains from bargaining. This requires:

$$
\begin{aligned}
-\left.\frac{G_{t}}{G_{T}}\right|_{d G=0} & <-\left.\frac{V_{t}}{V_{T}}\right|_{d V=0} \\
{\left[\pi^{\prime}(p+\hat{t}) \beta+t \pi^{\prime \prime}(p+t)\right] / \beta } & >\pi^{\prime}(p+\hat{t})
\end{aligned}
$$

This is always satisfied given the convexity of the profit function. Note that these equations imply that at $t=0$ we have $G_{t} / G_{T}=V_{t} / V_{T}$.

Necessity: Suppose a positive production externality is present. The optimal level of subsidy to address the externality is given by:

$$
t^{e x t}: G_{t}^{e x t}=0
$$

Where $G^{e x t}$ is the government objective reflecting the externality. For $t \geq t^{e x t}$ to be inefficient, it 
must be the case that when $t \geq t^{e x t}$,we have:

$$
\begin{aligned}
{\left[-\frac{G_{t}^{e x t}}{G_{T}^{e x t}}\right.} & \left.\leq-\frac{V_{t}}{V_{T}}\right]_{t \geq t^{e x t}} \\
{\left[\frac{G_{t}^{e x t}}{a \beta /(1-\beta)}\right.} & \left.\leq-\pi_{i}^{\prime}(p+\hat{t})\right]_{t \geq t^{e x t}}
\end{aligned}
$$

But since $G_{t}^{e x t}\left(t=t^{e x t}\right)=0$ by the definition of $t^{e x t}$ and $\pi^{\prime}\left(p+t=t^{e x t}\right)>0,(17)$ cannot hold. Hence, $t$ is not inefficient when an externality is present.

\section{Proofs}

\section{Proposition 1:}

In the absence of alternative transfer policies to lobbies the government chooses a cap on the efficient transfer that is strictly binding at $\left(C^{N}, T^{N}\right)$ iff neither player has all the bargaining power.

Proof: Sufficiency:

Suppose that $\gamma \in(0,1)$. We need only show the existence of a cap such that $T^{c}<T^{N}$ and $G\left(C^{N c}, T^{N c}\right)>G\left(C^{N}, T^{N}\right)$. The solution is illustrated in Figure 3. We first show that the constrained Pareto frontier is strictly concave. On the basis of that, we then show that $g^{N c}>g^{N}$.

The constrained Pareto frontier in Figure 3 coincides with the original one for $T \leq T^{c}$ and thus its slope is simply $\frac{G_{T}}{V_{T}}$ up to point $\left(C^{N}, T^{c}\right)$. From $(7)$ we have $\frac{G_{T}}{G_{C}}=\frac{V_{T}}{V_{C}}$ at $\left(C^{N}, T^{c}\right)$ so that $\frac{G_{T}}{V_{T}}=\frac{G_{C}}{V_{C}}$. The rest of the constrained frontier is strictly interior to the unconstrained frontier and has a slope of $\frac{G_{C}}{V_{C}}$, reflecting the ratio of changes in welfare as the amount of the lobby good provided changes. Moreover, $\frac{G_{C}\left(C^{N}\right)}{V_{C}}=-\Psi^{\prime}\left(C^{N}\right)>-\Psi^{\prime}\left(C<C^{N}\right)=\frac{G_{C}\left(C<C^{N}\right)}{V_{C}}$, from the definitions of $G$ and $V$ as well as $\Psi^{\prime \prime}<0$, so the constrained frontier is strictly concave. Now define point $A$ in Figure 3 as the intersection of the constrained frontier and $G=g^{N}$. Since the constrained frontier is strictly concave and $g^{m c}=g^{m}$ for $T^{c} \geq T^{0}$ (see Figure 2), the segment connecting $g^{m}$ and $A$ is everywhere below the constrained Pareto frontier.

Consider then an auxiliary problem where the Pareto frontier is defined by the straight line through $g^{m}$ and $A$, which has some slope $m$. For any linear Pareto frontier the government equilibrium utility is $g^{N}-g^{0}=\gamma\left(g^{m}-g^{0}\right)$ (from (10)). Since the straight line through $g^{m}$ and $A$ is a rotation of the original Pareto frontier inwards around $g^{m}$, and since $g^{m}-g^{0}$ and $\gamma$ are unchanged in the auxiliary problem, the equilibrium government utility is also unchanged. Therefore if we derive the first-order condition for this auxiliary problem as we do for (8) we obtain $-\left.\frac{U_{V}}{U_{G}}\right|_{A}=m$. Strict concavity of the constrained frontier implies that at $A, m>\left.\frac{G_{C}}{V_{C}}\right|_{A}$, the slope of the constrained frontier at $A$. Therefore, the equilibrium point $N^{C}$ lies to the northwest of $A$, implying $g^{N c}>g^{N}$.

Necessity.

If $\gamma=1$ then the unconstrained solution is $g^{m} \equiv \operatorname{Max}_{C, T} G$ s.t. $V=V^{0}$. The equilibrium transfer is $T^{N}(\gamma=1)=T^{0}$. A strictly binding cap entails that the government's utility is now $g^{m c} \equiv \operatorname{Max}_{C, T} G$ s.t. $V=V^{0}$ and $T^{c}<T^{0}$, the extra constraint implies that $g^{m c}<g^{m}$.

If $\gamma=0$ then the second stage Nash bargaining solution is $G^{N c}\left(T^{N c}, C^{N c}\right)=G(0,0)$. The government is therefore indifferent among all values of $T^{c}$, which implies that there exist $T^{c} \geq T^{N}$ (that is, caps that are not strictly binding) that are subgame perfect equilibria.

\section{Proposition 2:}

In the political equilibrium, there is:

a. a cap on the efficient transfer, $T$, that is strictly binding iff neither player has all the bargaining 
power; and

$b$. use of the relatively inefficient transfer policy, $t$.

\section{Proof:}

a. $T^{c}$ binds iff the government does not have all the bargaining power.

In the political equilibrium $T^{c}$ must satisfy the following FOC

$$
\frac{d G}{d T^{c}}=0
$$

where $\frac{d G}{d T^{c}} \equiv G_{C} C_{T^{c}}+G_{T} T_{T^{c}}+G_{t} t$. Note that $T_{T^{c}}=1$ since a marginal increase in the binding cap $T^{c}$ will induce an equivalent increase in the transfer. Thus, to show the gain from capping $T$, a proof similar to that in proposition 1 applies provided that the Pareto frontier is strictly concave when $T^{c}$ binds and $t$ is available.

The slope of the Pareto frontier is $\frac{G_{T}}{V_{T}}$ if $T^{c}$ is not binding. If $T^{c}$ binds then any further increases in the utility of the lobby must take place via changes in $C$ being exchanged for $t$, since as we will see $t^{c}>0$ when the externality is sufficiently important. Thus, if $T^{c}$ binds, the slope is $\frac{G_{t} d t-G_{C} d C}{V_{t} d t-V_{C} d C}=\frac{G_{t}}{V_{t}}$ since the equilibrium definition requires $t$ and $C$ to be set efficiently, i.e. for $\frac{G t}{G_{C}}=\frac{V t}{V_{C}}$. Therefore we have

$$
\begin{aligned}
\lim _{t \rightarrow 0} \frac{G_{t}}{V_{t}} & =\frac{G_{T}}{V_{T}} \\
& >\left.\frac{G_{t}}{V_{t}}\right|_{t>0}
\end{aligned}
$$

where the first equality is due to the definition of $G$ and $V$. (As shown in the proof of Lemma 1 in the appendix, as $t \rightarrow 0, \frac{G_{t}}{V_{t}}=\frac{G_{T}}{V_{T}}$, that is, the utility frontier for efficient and inefficient transfers has the same slope.) The inequality follows from the definition of $t$ being inefficient relative to $T$. Thus the constrained Pareto frontier is strictly concave and we can apply the proof of proposition 1 to show that $\hat{T}^{c}$ binds.

b. $\hat{t}>0$ in equilibrium.

Suppose $\hat{t}=0$. Since $T^{c}$ is optimally chosen and binds the constrained solution would lie at the point where the new Pareto frontier meets the original one in Figure 4. However, since the unique unconstrained solution was $\hat{t}=0, T^{N}>T^{c}$ and the slope of the frontiers is identical when $\hat{t}=0$ the constrained solution cannot be $T^{c}, \hat{t}=0$.

\section{Proposition 3:}

a. Given a discrete choice of the transfer policy to use in bargaining with a lobby the government chooses a relatively more inefficient transfer, $t$, instead of $T$ if:

i. $\lim _{\gamma \rightarrow 0}\left(1 / \Omega^{\prime t}\right) /\left(1 / \Omega^{\prime T}\right)>\lim _{\gamma \rightarrow 0} \Omega^{T} / \Omega^{t}$ and

ii. $\gamma \in\left(0, \gamma^{*}\right)$

b. Moreover, there exists $a \bar{\gamma} \in\left[\gamma^{*}, 1\right)$ s.t. the government always chooses $T$ when $\gamma \in(\bar{\gamma}, 1]$.

\section{Proof:}

a. When $\gamma=0$ we have $G\left(0, t^{N t}(\gamma), C^{N t}(\gamma)\right)=G\left(T^{N}(\gamma), 0, C^{N}\right)=g^{0}$. Equation (13) is thus sufficient to show (12) is satisfied for $\gamma \in\left(0, \gamma^{*}\right)$. To evaluate (13), we first use the implicit function theorem to obtain $\lim _{\gamma \rightarrow 0} d g / d \gamma=\lim _{\gamma \rightarrow 0}-\hat{L}_{G \gamma} / \hat{L}_{G G}$ where $\hat{L}$ is the Nash product evaluated at the solution of the following program

$$
\operatorname{Max}_{G \geq g^{0}} L \equiv\left(G-g^{0}\right)^{\gamma}\left(\Omega\left(G-g^{0}\right)\right)^{1-\gamma}
$$


The FOC $L_{G}=0$ is

$$
\begin{aligned}
\gamma\left(\frac{\Omega}{G-g^{0}}\right)^{1-\gamma}+(1-\gamma)\left(\frac{G-g^{0}}{\Omega}\right)^{\gamma} \Omega^{\prime} & =0 \\
G-g^{0} & =-\frac{\Omega}{\Omega^{\prime}} \frac{\gamma}{1-\gamma}
\end{aligned}
$$

Using this we have $\hat{L}_{G \gamma}=\hat{L} /(1-\gamma)\left(\hat{G}-g^{0}\right)$ and $\hat{L}_{G G}=\left(-\gamma\left(\frac{1}{1-\gamma}\right)+(1-\gamma) \hat{\Omega}^{\prime \prime} \frac{\left(\hat{G}-g^{0}\right)^{2}}{\hat{\Omega}}\right) \hat{L} /\left(\hat{G}-g^{0}\right)^{2}$, which we use to obtain after some simplification

$$
\begin{aligned}
\lim _{\gamma \rightarrow 0} d \hat{g} / d \gamma & =\lim _{\gamma \rightarrow 0}-\hat{L}_{G \gamma} / \hat{L}_{G G} \\
& =\lim _{\gamma \rightarrow 0}-\frac{\hat{\Omega}}{\hat{\Omega}^{\prime}}
\end{aligned}
$$

Therefore (13) reduces to the condition in (i): $\lim _{\gamma \rightarrow 0}\left(1 / \hat{\Omega}^{\prime t}\right) /\left(1 / \hat{\Omega}^{\prime T}\right)>\lim _{\gamma \rightarrow 0} \hat{\Omega}^{T} / \hat{\Omega}^{t}$.

b. At $\gamma=1$ we have $g^{m}>g^{m t}$ thus the government chooses $T$. Since the inequality is strict and $G$ is continuous in $\gamma\left(G\right.$ is continuous in the policies and $\left(t^{N t}(\gamma), C^{N t}(\gamma)\right)$ and $T^{N}(\gamma)$ are continuous in $\gamma$ ) we can find a $\bar{\gamma}<1$ s.t. $g^{N}(\bar{\gamma})=g^{N t}(\bar{\gamma})$. If (14) has a unique solution, then $\bar{\gamma}=\gamma^{*}$. Otherwise $\bar{\gamma}$ is the maximum $\gamma$ that satisfies (14).

Lemma 2: Under $P_{x}\left(a_{x}, \gamma=\gamma^{*}\left(a_{x}\right)\right)$, a majority prefers $t$ to $T$ iff $\sum_{i \in L} \alpha_{i}<0.5$.

Proof: Organized Sectors: Since $t$ is inefficient the joint surplus from bargaining with each lobby is lower relative to $T$ as shown in lemma 1. $P_{x}$ is indifferent between $t$ and $T$ by the definition of $\gamma^{*}$. Therefore each lobby is worse off under $t$ and prefers $T$. They are a majority when $\sum_{i \in L} \alpha_{i}>0.5$.

Unorganized Sectors and Workers: To show that unorganized sectors $j$ and workers $\ell$ prefer $t$ to $T$ under $P_{x}\left(a_{x}, \gamma_{x}=\gamma^{*}\left(a_{x}\right)\right)$, we show that first that $C^{N t}<C^{N}$ and then that this implies total social welfare is higher under $t$ than $T$ when the politician's bargaining power is $\gamma_{x}=\gamma^{*}\left(a_{x}\right)$. Since the organized lobbies are worse off under $t$, other groups must be better off.

Step 1: $C^{N t}<C^{N}-$ From (7) we have $\Psi^{\prime}\left(C^{N}\right)=\frac{a \beta}{1-\beta}$ when only $T$ is used. The contract curve when only $t$ is used is defined by $\frac{G_{t}}{G_{C}}=\frac{V_{t}}{V_{C}}$, implying

$$
\Psi^{\prime}(C)=\frac{a \beta}{1-\beta}+\frac{a t \pi^{\prime \prime}(p+t)}{(1-\beta) \pi^{\prime}(p+t)}
$$

so that $\Psi^{\prime}\left(C^{N t}\right)-\Psi^{\prime}\left(C^{N}\right)=\frac{a t \pi^{\prime \prime}(p+t)}{(1-\beta) \pi^{\prime}(p+t)}>0$, where the inequality follows from $\pi^{\prime}, \pi^{\prime \prime}>0 . \Psi^{\prime}\left(C^{N t}\right)>$ $\Psi^{\prime}\left(C^{N}\right) \Longrightarrow C^{N t}<C^{N}$ because $\Psi^{\prime \prime}<0$.

Step 2: $\hat{W}\left(0, t\left(a_{x}, \gamma_{x}=\gamma^{*}\left(a_{x}\right)\right)>\hat{W}\left(T\left(a_{x}, \gamma_{x}=\gamma^{*}\left(a_{x}\right), 0\right)\right.\right.$ at $\gamma^{*}$ - From the definition of $\gamma^{*}$ in (14) we have $G\left(0, t^{N t}\left(\gamma^{*}\right), C^{N t}\left(\gamma^{*}\right)\right)=G\left(T^{N}\left(\gamma^{*}\right), 0, C^{N}\right)$, so that

$$
W\left(0, t^{N t}\left(\gamma^{*}\right)\right)-W\left(T^{N}\left(\gamma^{*}\right), 0\right)=\frac{\Psi\left(C^{N}\right)-\Psi\left(C^{N t}\left(\gamma^{*}\right)\right)}{a}>0
$$

where the inequality follows from $C_{i}^{N t}<C_{i}^{N}$.

Step 3: $\hat{W}_{\ell}\left(0, t\left(a_{x}, \gamma_{x}=\gamma^{*}\left(a_{x}\right)\right)>\hat{W}_{\ell}\left(T\left(a_{x}, \gamma_{x}=\gamma^{*}\left(a_{x}\right), 0\right)\right.\right.$ for workers and $\hat{W}_{j}\left(0, t\left(a_{x}, \gamma_{x}=\right.\right.$ $\left.\gamma^{*}\left(a_{x}\right)\right)>\hat{W}_{j}\left(T\left(a_{x}, \gamma_{x}=\gamma^{*}\left(a_{x}\right), 0\right)\right.$ for unorganized sectors- We can decompose social welfare as:

$$
W^{t}-W^{T} \equiv \sum_{i}\left(W_{i}^{t}-W_{i}^{T}\right)+\sum_{j}\left(W_{j}^{t}-W_{j}^{T}\right)+W_{\ell}^{t}-W_{\ell}^{T}
$$


which is positive at $\gamma^{*}$ from step 2. We may then write

$$
\begin{aligned}
\sum_{j}\left(W_{j}^{t}-W_{j}^{T}\right)+W_{\ell}^{t}-W_{\ell}^{T} & >\sum_{i}\left(W_{i}^{T}-W_{i}^{t}\right) \\
& =\sum_{i}\left(V_{i}^{T}+C_{i}^{T}-\left(V_{i}^{t}+C_{i}^{t}\right)\right) \\
& =\sum_{i}\left(V_{i}^{T}-V_{i}^{t}+C_{i}^{N}-C_{i}^{N t}\right)>0
\end{aligned}
$$

where the last inequality follows from the inefficiency of $t$ and the fact that at $\gamma^{*}$ the government is indifferent so the lobby must be worse off, as shown above, and from $C_{i}^{N}>C_{i}^{N t}$.

Moreover $\operatorname{sign}\left(W_{j}^{t}-W_{j}^{T}\right)=\operatorname{sign}\left(W_{\ell}^{t}-W_{\ell}^{T}\right)$ for all $j$. Therefore $\sum_{j}\left(W_{j}^{t}-W_{j}^{T}\right)+W_{\ell}^{t}-W_{\ell}^{T}>0$ implies that $W_{j}^{t}>W_{j}^{T}$ for all $j$ and $W_{\ell}^{t}>W_{\ell}^{T}$.

\section{Proposition 4:}

When $d \gamma^{*} / d a>0$ a politician $P_{t}\left(a_{t}>a, \gamma=\gamma^{*}(a)\right)$ implements the inefficient policy. Moreover, if $\sum_{i \in L} \alpha_{i}<0.5$ then $P_{t}$ wins a majority vote against all politicians with the same bargaining power that implement $T, P_{T}\left(a_{T}<a, \gamma\right)$.

When $d \gamma^{*} / d a<0$ a politician $P_{t}\left(a_{t}<a, \gamma_{t}=\gamma^{*}(a)\right)$ implements the inefficient policy. Moreover if $\sum_{i \in L} \alpha_{i}<0.5$ then $P_{t}$ wins a majority vote against all politicians with the same bargaining power that implement $T, P_{T}\left(a_{T}>a, \gamma\right)$, unless $P_{T}$ cares sufficiently more about social welfare than $P_{t}$, that is unless $a_{T}-a_{t}>0$ is sufficiently large.

\section{Proof:}

Case 1: $d \gamma^{*} / d a>0$. Now a politician with higher $a$ ( lower $a$ ) prefers $t(T)$. For example $P_{t}\left(a_{t}>\right.$ $\left.a, \gamma_{t}=\gamma^{*}(a)\right)$ prefers $t$ since $\gamma_{t}=\gamma^{*}(a)<\gamma^{*}\left(a_{t}>a\right)$. So for a given $\gamma$ only a politician with lower $a$ implements $T$. Since according to lemma 2 the majority of voters prefer $t$ when $\gamma=\gamma^{*}(a)$ and for a given policy voters prefer politicians which place higher value on social welfare they always elect a politician that implements the inefficient policy.

Case 2: $d \gamma^{*} / d a<0$. Now a politician with lower $a$ (higher $a$ ) prefers $t(T)$. Since $\lim _{\varepsilon \rightarrow 0}\left(W^{t}(t(a-\right.$ $\left.\left.\left.\varepsilon, \gamma^{*}(a-\varepsilon)\right)\right)>W^{T}\left(T\left(a+\varepsilon, \gamma^{*}(a+\varepsilon)\right)\right)\right)$ there is some $\varepsilon>0$ s.t. $W^{t}\left(t\left(a-\varepsilon, \gamma^{*}(a-\varepsilon)\right)\right)>W^{T}(T(a+$ $\left.\left.\varepsilon, \gamma^{*}(a+\varepsilon)\right)\right)$ and thus there is always some $\varepsilon>0$ s.t. $P_{t}\left(a_{t}=a-\varepsilon, \gamma_{t}=\gamma^{*}(a)\right)$ is elected. As $\varepsilon$ increases $W^{t}\left(t\left(a-\varepsilon, \gamma^{*}(a-\varepsilon)\right)\right.$ falls and $W^{T}\left(T\left(a+\varepsilon, \gamma^{*}(a+\varepsilon)\right)\right)$ increases until for some sufficiently large $\varepsilon$ they are equal.

\section{Slope of the Contract Curve with Production Subsidies}

In this appendix, we show that as long as the supply function is not too concave or convex, the contract curve in $C, t$ space is downward sloping. The contract curve is defined by the following efficiency condition

$$
\begin{aligned}
-\frac{G_{t}}{G_{C}} & =-\frac{V_{t}}{V_{C}} \\
\Psi^{\prime}(C) & =\frac{a \beta}{1-\beta}+\frac{a t \pi^{\prime \prime}(p+t)}{(1-\beta) \pi^{\prime}(p+t)}
\end{aligned}
$$

Implicitly differentiating and using $\Psi^{\prime \prime}<0$ we obtain:

$$
\left.\frac{d C}{d t}\right|_{C C}=\left\{\frac{a}{1-\beta}\left(\frac{\left.\pi^{\prime \prime}(p+t)+t \pi^{\prime \prime \prime}(p+t)\right)}{\pi^{\prime}(p+t)}-t\left(\frac{\pi^{\prime \prime}(p+t)}{\pi^{\prime}(p+t)}\right)^{2}\right)\right\} / \Psi^{\prime \prime}(C)
$$




$$
\begin{aligned}
\operatorname{sign}\left(\left.\frac{d C}{d t}\right|_{C C}\right) & =-\operatorname{sign}\left(\frac{\left.\pi^{\prime \prime}(p+t)+t \pi^{\prime \prime \prime}(p+t)\right)}{\pi^{\prime}(p+t)}-t\left(\frac{\pi^{\prime \prime}(p+t)}{\pi^{\prime}(p+t)}\right)^{2}\right) \\
& =-\operatorname{sign}\left(\left(\pi^{\prime \prime}(p+t)+t \pi^{\prime \prime \prime}(p+t)\right) \pi^{\prime}(p+t)-t\left(\pi^{\prime \prime}(p+t)\right)^{2}\right)
\end{aligned}
$$

When $t \rightarrow 0^{+}$

$$
\operatorname{sign}\left(\left.\frac{d C}{d t}\right|_{C C}\right)=-\operatorname{sign}\left(\pi^{\prime \prime}(p) \pi^{\prime}(p)\right)<0
$$

When $\pi^{\prime \prime \prime} \rightarrow 0$, i.e. approximately linear supply, we obtain for all $t$

$$
\operatorname{sign}\left(\left.\frac{d C}{d t}\right|_{C C}\right)=-\operatorname{sign}\left(\pi^{\prime}(p+t)-t \pi^{\prime \prime}(p+t)\right)<0
$$

Since when $\pi^{\prime \prime \prime} \rightarrow 0$ we have $\pi^{\prime \prime}(p+t) \approx \pi^{\prime}(p+t) /(p+t)$ and thus we can rewrite $\left(\pi^{\prime \prime}(p+t)+t \pi^{\prime \prime \prime}(p+\right.$ $\left.t) \pi^{\prime}(p+t)-t\left(\pi^{\prime \prime}(p+t)\right)^{2} \approx\{1-t /(p+t))\right\}\left(\pi^{\prime}(p+t)\right)^{2} /(p+t)>0$.

Note also that if $\operatorname{sign}\left(\left.\frac{d C}{d t}\right|_{C C}\right)<0$ then the Pareto frontier when $t$ is used is globally concave. To see this note that the slope of the Pareto frontier is $G_{C} / V_{C}$. It is globally concave if lobby goods

are higher when the government has more bargaining power, ensured by $\operatorname{sign}\left(\left.\frac{d C}{d t}\right|_{C C}\right)<0$, and $\left.\left(G_{C} / V_{C}\right)\right|_{\text {Chigh }}>\left.\left(G_{C} / V_{C}\right)\right|_{\text {Clow }}$, which is ensured since $\Psi^{\prime \prime}<0$ and $V_{C}=-1$.

\section{E Simulation}

Assumptions: $\Psi \equiv C^{\psi}, \psi \in(0,1) ; q \equiv k^{1-\alpha} l^{\alpha} \Longrightarrow \pi(p+t)=(p+t) k(\alpha(p+t))^{\frac{\alpha}{1-\alpha}}, \alpha=.5$.

Slope condition for efficient transfer

$$
\begin{aligned}
\lim _{\gamma \rightarrow 0}-\frac{\Omega^{T}}{\Omega^{\prime T}} & =\lim _{\gamma \rightarrow 0} \Psi^{\prime}\left(C^{N}\right)\left(V-v^{0}\right) \\
& =\frac{a \beta}{1-\beta}\left(V^{m T}-v^{0}\right) \\
& =\frac{a \beta}{1-\beta}\left(T^{m}-C^{N}\right)
\end{aligned}
$$

The first equality is due to the definition of $\Omega$, the second is due to the first-order condition in (7). The last equality follows from the definition of $V^{m T}$, where $T^{m}$ represents the maximum transfer the lobby can extract and is defined by:

$$
\begin{aligned}
G(T & =0, t=0, C=0)=G\left(T^{m}, t=0, C^{N}\right) \\
T^{m} & =\Psi\left(C^{N}\right) / \frac{a \beta}{1-\beta}
\end{aligned}
$$

Using (21), $\Psi$ and the solution to $C^{N}$ in (7) we obtain the general condition to be evaluated:

$$
\begin{aligned}
\lim _{\gamma \rightarrow 0}-\frac{\Omega T}{\Omega^{\prime T}} & =\Psi\left(C^{N}\right)-\frac{a \beta}{1-\beta} C^{N} \\
& =\left(\frac{1-\psi}{\psi}\right) \frac{a \beta}{1-\beta} \exp \left(\frac{\ln \frac{a \beta}{\psi-\beta}}{\psi-1}\right)
\end{aligned}
$$

Slope condition for the inefficient transfer 


$$
\begin{aligned}
\lim _{\gamma \rightarrow 0}-\frac{\Omega^{t}}{\Omega^{\prime t}} & =\lim _{\gamma \rightarrow 0} \Psi^{\prime}\left(C^{N t}\right)\left(V-v^{0}\right) \\
& =\lim _{\gamma \rightarrow 0} \frac{a\left(\beta \pi^{\prime}(p+t)+t \pi^{\prime \prime}(p+t)\right)}{(1-\beta) \pi^{\prime}(p+t)}\left(V^{m T}-v^{0}\right)
\end{aligned}
$$

The first equality, is due to the definition of $\Omega$, the expression for $\Psi^{\prime}\left(C^{N t}\right)$ in the second equality is derived from the efficiency condition: $G_{t} / G_{C}=V_{t} / V_{C}$. Using the definition of $V$ we obtain $V^{m t}-v^{0}=\pi\left(p+t^{N}(\gamma=0)\right)-C^{m t}-\pi(p)$ where $C^{m t}$ is the minimum level of the good provided by the lobby required to maintain the government at the reservation utility. Using the definition of $G$ we can write $C^{m t}$ as

$$
\begin{gathered}
G(T=0, t=0, C=0)=G\left(T=0, t=t^{N}(\gamma=0), C^{m t}\right) \\
C^{m t}=\Psi^{-1}\left(-a\left(\pi\left(p+t^{N}(\gamma=0)\right)-\pi(p)-t \pi^{\prime}\left(p+t^{N}(\gamma=0)\right) /(1-\beta)\right)\right)
\end{gathered}
$$

Using (23), $\Psi, \pi(p+t)$ and (24) we obtain:

$$
\begin{gathered}
\lim _{\gamma \rightarrow 0}-\frac{\Omega^{t}}{\Omega^{\prime t}}=\left[\frac{a\left(\beta \pi^{\prime}\left(p+t^{N}\right)+t^{N} \pi^{\prime \prime}\left(p+t^{N}\right)\right)}{(1-\beta) \pi^{\prime}\left(p+t^{N}\right)}\left(\pi\left(p+t^{N}\right)-\pi(p)-C^{m t}\right)\right]_{\gamma=0} \\
\lim _{\gamma \rightarrow 0}-\frac{\Omega^{t}}{\Omega^{\prime t}}=\left[\frac{a\left(\beta k\left(p+t^{N}\right)+t^{N} k\right)}{(1-\beta) k\left(p+t^{N}\right)}\right. \\
\quad \times\left\{0.5\left(p+t^{N}\right)^{2} k-0.5 p^{2} k\right. \\
\left.\left.-\left(\left(-a\left(0.5\left(p+t^{N}\right)^{2} k-0.5 p^{2} k-t^{N} k\left(p+t^{N}\right) /(1-\beta)\right)\right)\right)^{1 / \psi}\right\}\right]_{\gamma=0}
\end{gathered}
$$

To calculate this we require the equilibrium $t$, which is obtained using the efficiency condition $G_{t} / G_{C}=V_{t} / V_{C}$ and $(24)$ :

$$
\begin{aligned}
& t^{N}: \quad \Psi^{-1}\left(-a\left(\pi(p+t)-\pi(p)-t \pi^{\prime}(p+t) /(1-\beta)\right)\right)=\Psi^{\prime-1}\left(\frac{a\left(\beta \pi^{\prime}(p+t)+t \pi^{\prime \prime}(p+t)\right)}{(1-\beta) \pi^{\prime}(p+t)}\right) \\
& t^{N}:\left(\left(-a\left(0.5(p+t)^{2} k-0.5 p^{2} k-t k(p+t) /(1-\beta)\right)\right)\right)^{1 / \psi}=\left(\frac{1}{\psi}\left(\frac{a(\beta k(p+t)+t k)}{(1-\beta) k(p+t)}\right)\right)^{-1 /(1-\psi)}
\end{aligned}
$$

Evaluating (22) and (25) at the parameter values below we obtain the results in table 1 in section 5.2 . 
Figure 1: Efficient Transfer

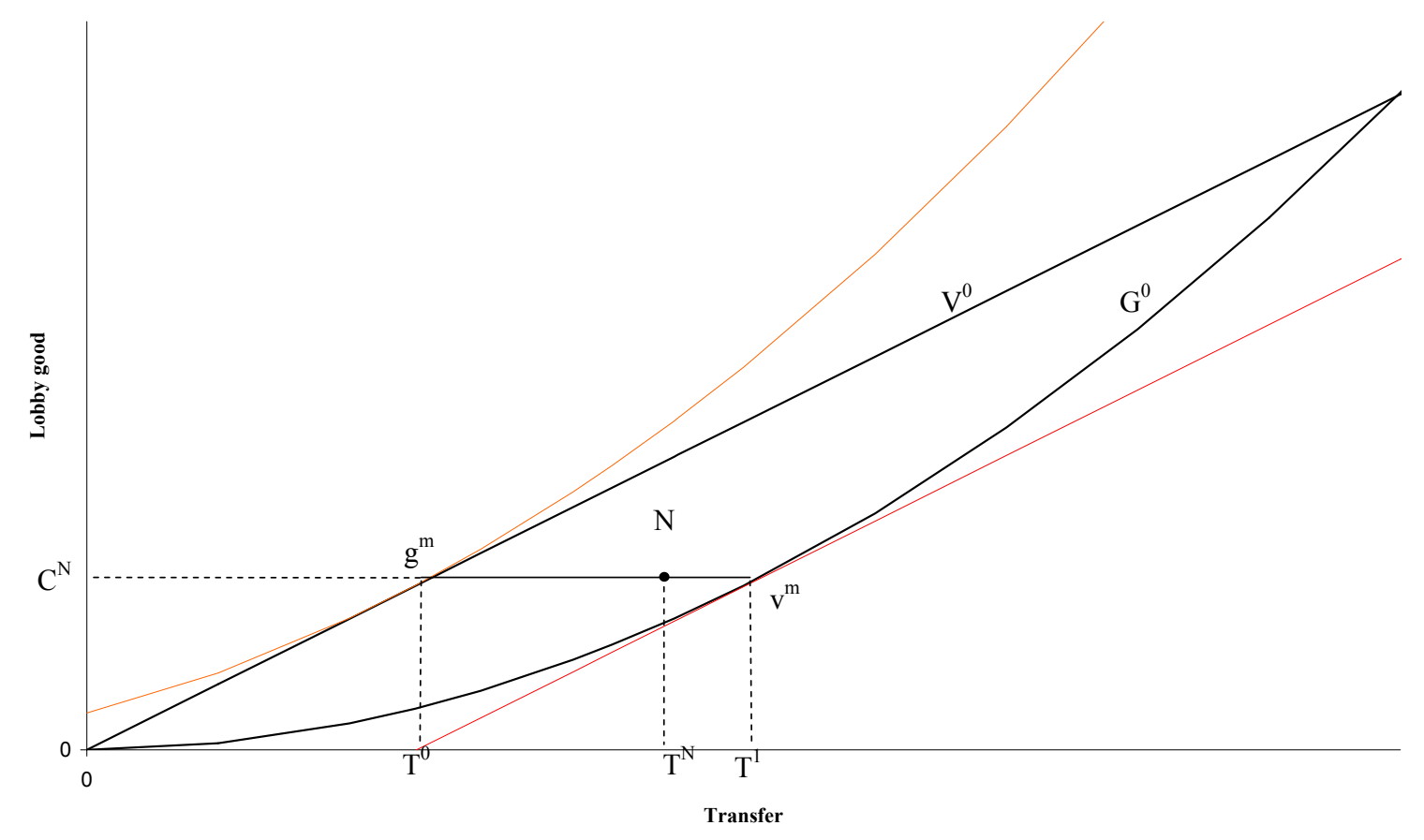

Figure 2: Cap on Efficient Transfer

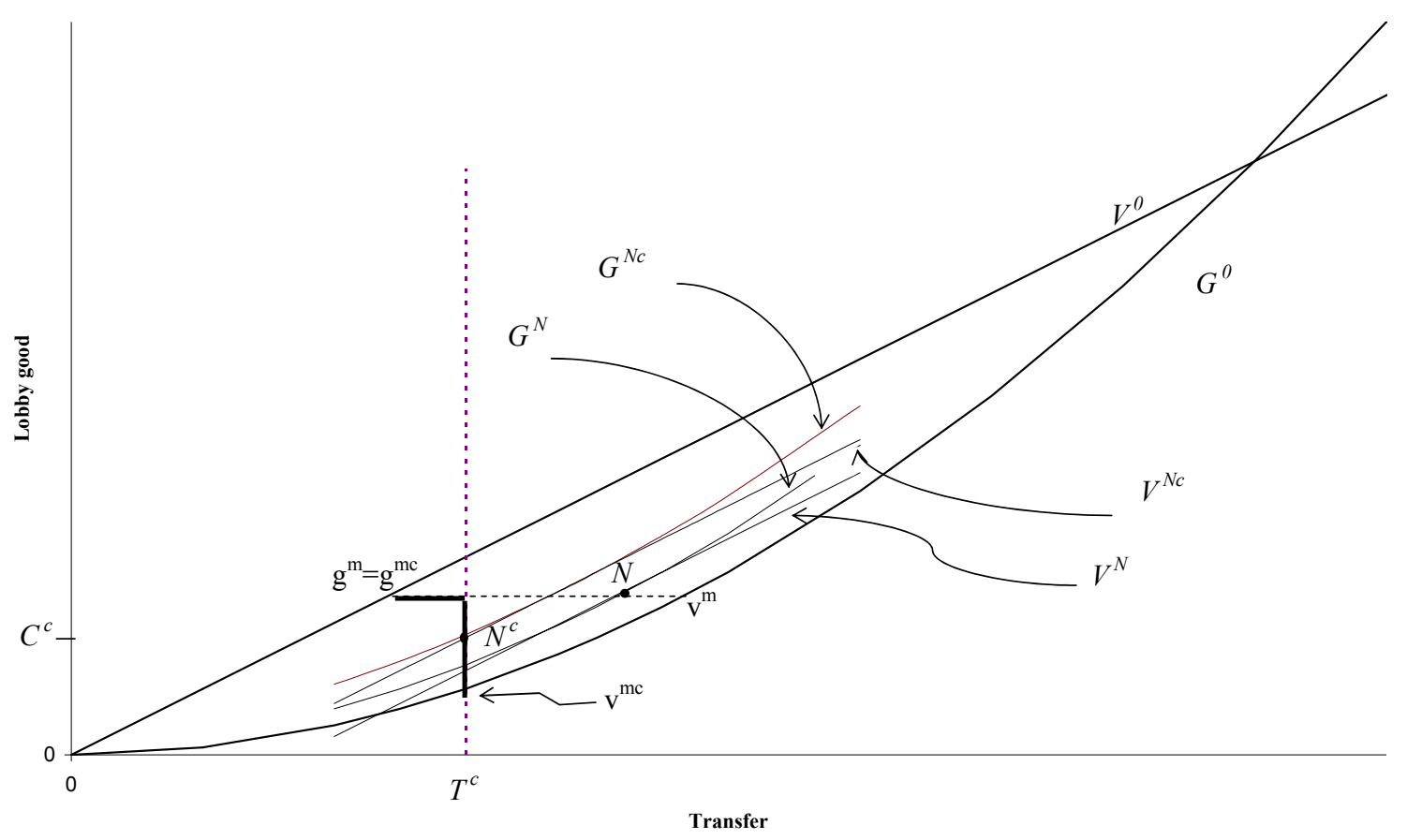


Figure 3: Bargaining Solution with Cap on Efficient Transfer

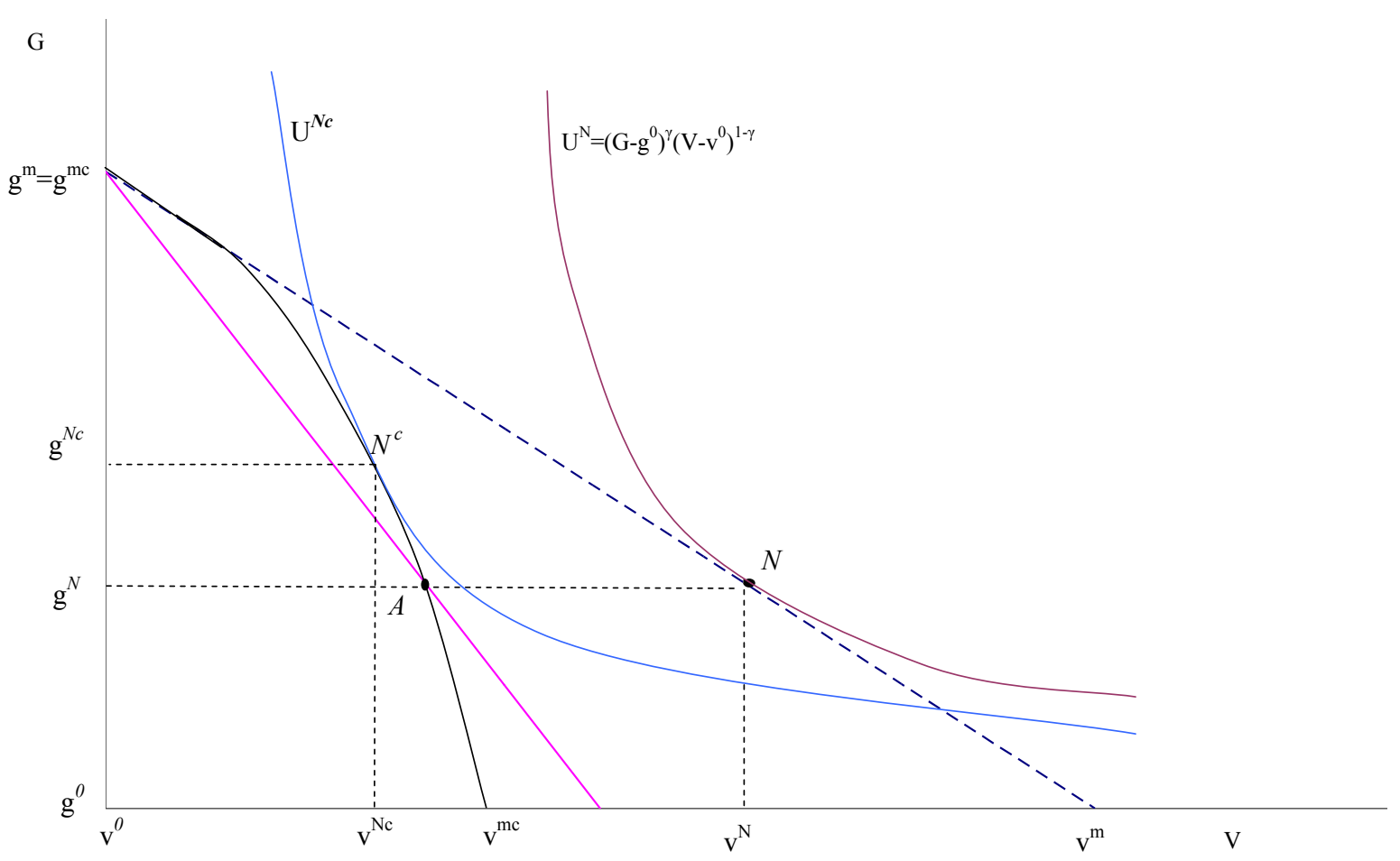

Figure 4: Bargaining Solution with Inefficient Transfers

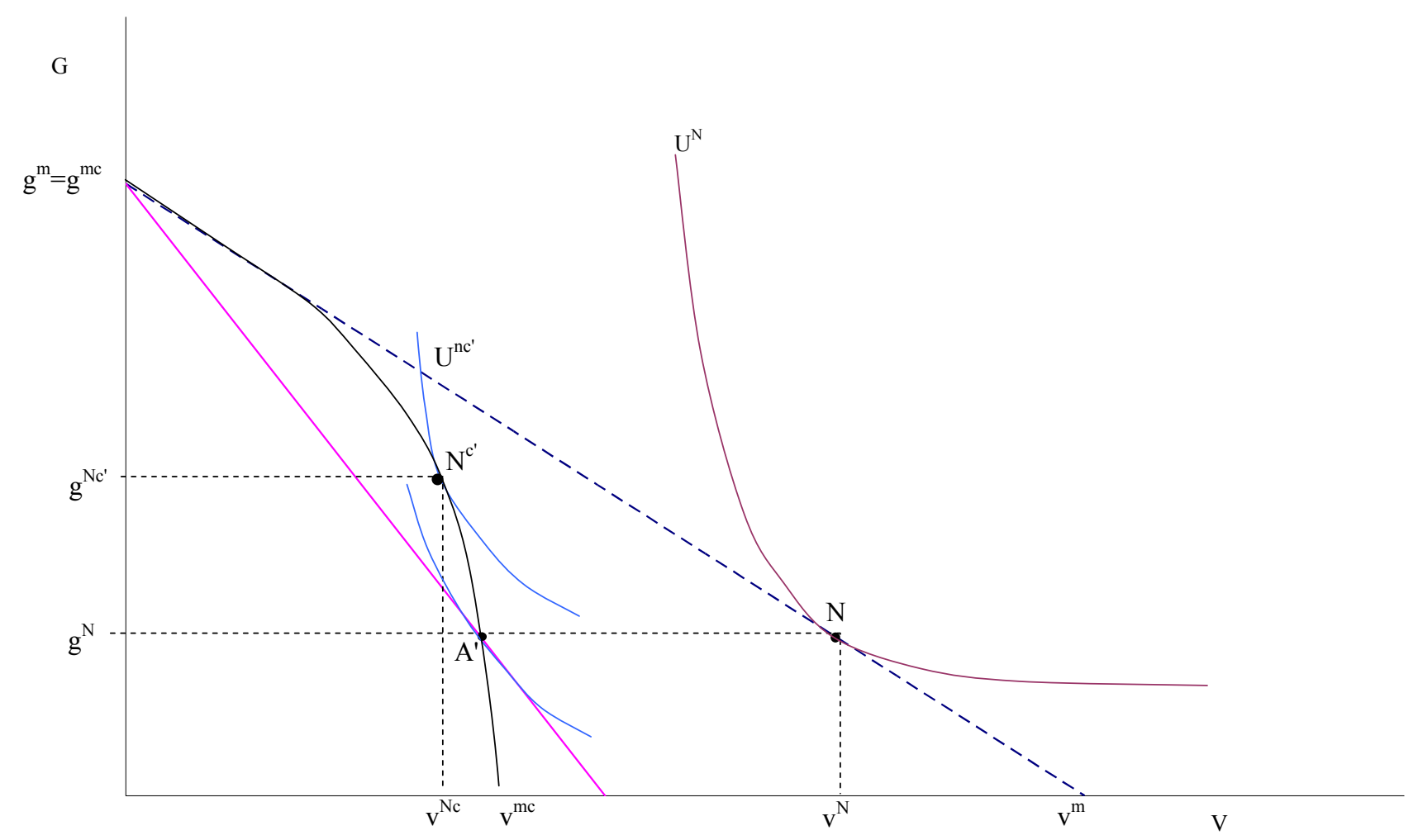


Figure 5

Government's optimal redistribution policy

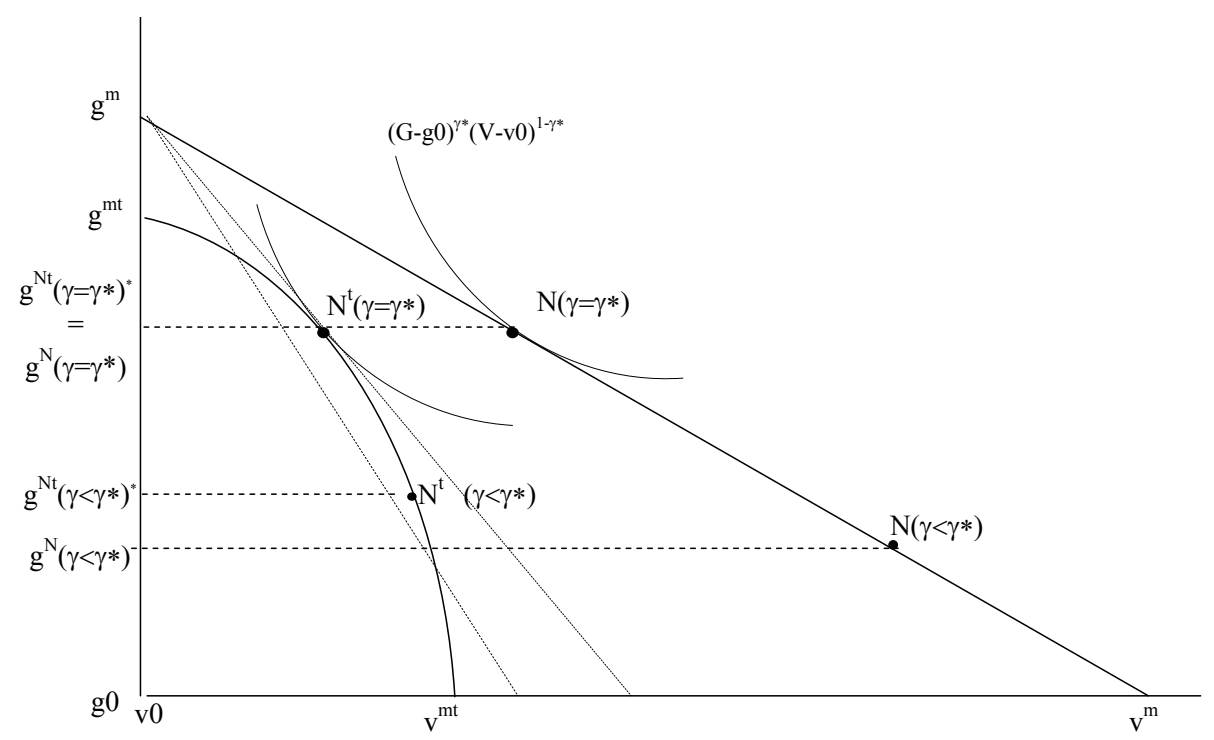

Figure 6

Bargaining power and the government's optimal redistribution policy

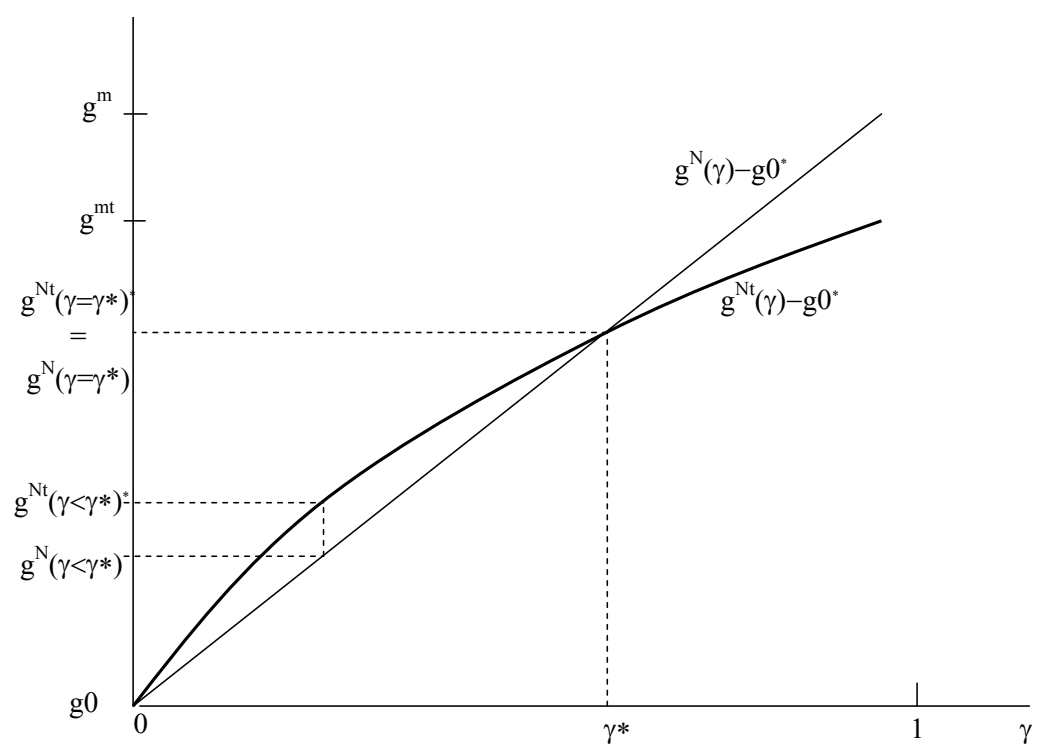


Figure 7: Bargaining Solution for caps in $1^{\text {st }}$ stage

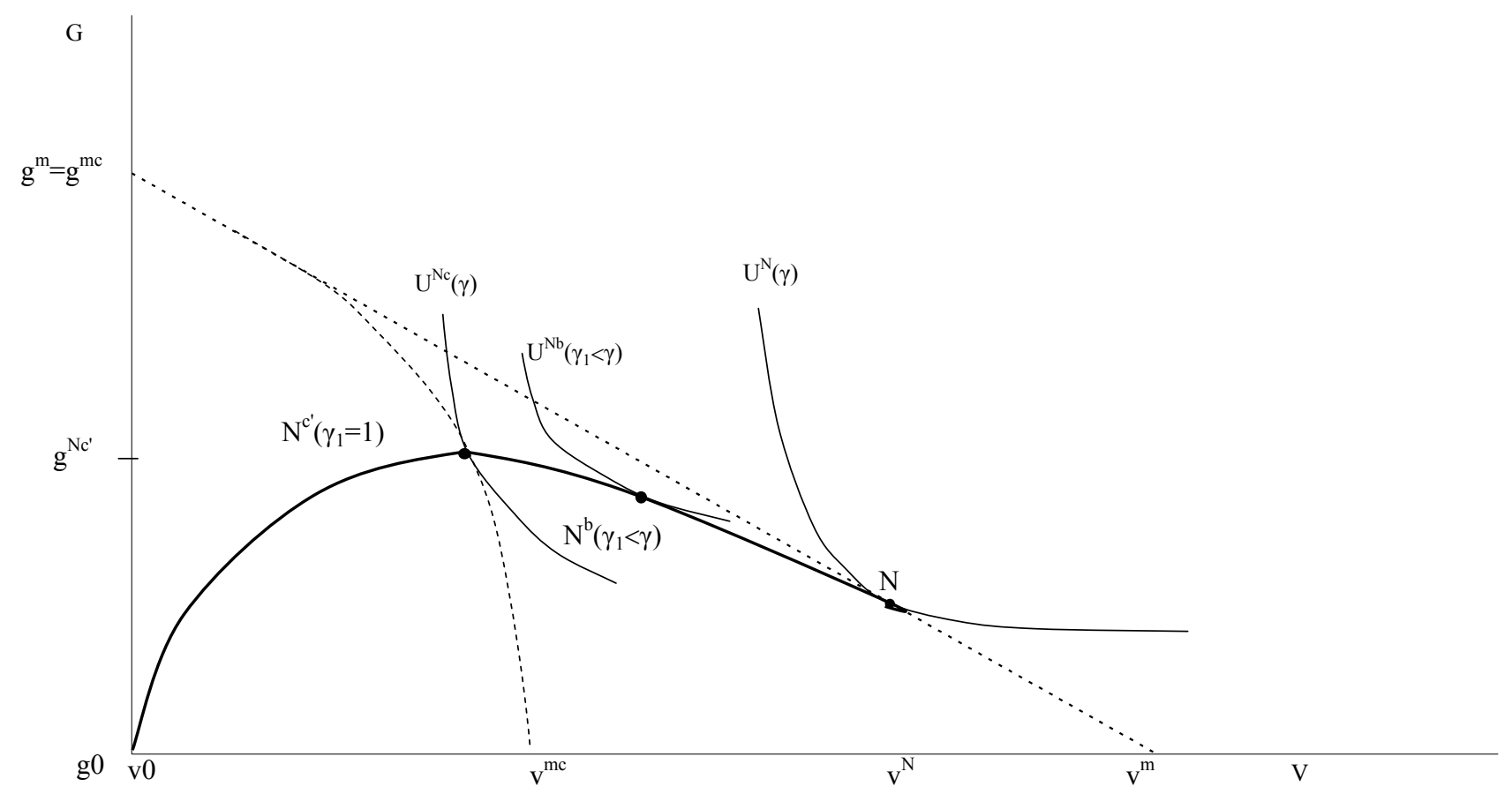


To order any of these papers in hard copy, see instructions at the end of this list. To subscribe to all NBER Working Papers or the papers in a single area, see instructions inside the back cover.

\begin{tabular}{|c|c|c|c|}
\hline Number & $\underline{\text { Author(s) }}$ & $\underline{\text { Title }}$ & $\underline{\text { Date }}$ \\
\hline 10318 & $\begin{array}{l}\text { Anusha Chari } \\
\text { Peter Blair Henry }\end{array}$ & $\begin{array}{l}\text { Is the Invisible Hand Discerning or Indiscriminate? } \\
\text { Investment and Stock Prices in the Aftermath of } \\
\text { Capital Account Liberalizations }\end{array}$ & $2 / 04$ \\
\hline 10319 & $\begin{array}{l}\text { Tibor Besedes } \\
\text { Thomas J. Prusa }\end{array}$ & $\begin{array}{l}\text { Surviving the U.S. Import Market: } \\
\text { The Role of Production Differentiation }\end{array}$ & $2 / 04$ \\
\hline 10320 & $\begin{array}{l}\text { Casey B. Mulligan } \\
\text { Yona Rubinstein }\end{array}$ & $\begin{array}{l}\text { Household vs. Personal Accounts of the } \\
\text { U.S. Labor Market, 1965-2000 }\end{array}$ & $2 / 04$ \\
\hline 10321 & James Poterba & Taxation and Corporate Payout Policy & $2 / 04$ \\
\hline 10322 & $\begin{array}{l}\text { Todd Sinai } \\
\text { Joseph Gyourko }\end{array}$ & $\begin{array}{l}\text { The (Un)Changing Geographical Distribution of } \\
\text { Housing Tax Benefits: } 1980 \text { to } 2000\end{array}$ & $2 / 04$ \\
\hline 10323 & $\begin{array}{l}\text { Ralph Siebert } \\
\text { Klaus Gugler }\end{array}$ & $\begin{array}{l}\text { Market Power versus Efficiency Effects of Mergers } \\
\text { and Research Joint Ventures: } \\
\text { Evidence from the Semiconductor Industry }\end{array}$ & $2 / 04$ \\
\hline 10324 & $\begin{array}{l}\text { Michael Kremer } \\
\text { Edward Miguel }\end{array}$ & The Illusion of Sustainability & $2 / 04$ \\
\hline 10325 & $\begin{array}{l}\text { Judith K. Hellerstein } \\
\text { David Neumark }\end{array}$ & $\begin{array}{l}\text { Production Function and Wage Equation Estimation } \\
\text { with Heterogeneous Labor: Evidence from a New } \\
\text { Matched Employer-Employee Data Set }\end{array}$ & $2 / 04$ \\
\hline 10326 & Robert Shimer & The Consequences of Rigid Wages in Search Models & $2 / 04$ \\
\hline 10327 & Dimitri Vayanos & $\begin{array}{l}\text { Flight to Quality, Flight to Liquidity, } \\
\text { and the Pricing of Risk }\end{array}$ & $2 / 04$ \\
\hline 10328 & Frank R. Lichtenberg & $\begin{array}{l}\text { The Expanding Pharmaceutical Arsenal } \\
\text { in the War on Cancer }\end{array}$ & $2 / 04$ \\
\hline 10329 & Michael D. Bordo & $\begin{array}{l}\text { Good versus Bad Deflation: Lessons from the } \\
\text { Gold Standard Era }\end{array}$ & $2 / 04$ \\
\hline 10330 & $\begin{array}{l}\text { Sarah E. West } \\
\text { Roberton C. Williams }\end{array}$ & $\begin{array}{l}\text { Empirical Estimates for Environmental Policy } \\
\text { Making in a Second-Best Setting }\end{array}$ & $3 / 04$ \\
\hline 10331 & Claudia Goldin & The Long Road to the Fast Track: Career and Family & $3 / 04$ \\
\hline 10332 & $\begin{array}{l}\text { Michael P. Dooley } \\
\text { David Folkerts-Landau } \\
\text { Peter Garber }\end{array}$ & $\begin{array}{l}\text { The Revived Bretton Woods System: The Effects of } \\
\text { Periphery Intervention and Reserve Management on } \\
\text { Interest Rates and Exchange Rates in Center Countries }\end{array}$ & $3 / 04$ \\
\hline 10333 & Brian Knight & $\begin{array}{l}\text { Are Policy Platforms Capitalized into Equity Prices? } \\
\text { Evidence from the Bush/Gore } 2000 \text { Presidential Election }\end{array}$ & $n^{3 / 04}$ \\
\hline
\end{tabular}


To order any of these papers in hard copy, see instructions at the end of this list. To subscribe to all NBER Working Papers or the papers in a single area, see instructions inside the back cover.

\begin{tabular}{|c|c|c|c|}
\hline Number & Author(s) & $\underline{\text { Title }}$ & Date \\
\hline 10334 & $\begin{array}{l}\text { Angelique Augereau } \\
\text { Shane Greenstein } \\
\text { Marc Rysman }\end{array}$ & $\begin{array}{l}\text { Coordination vs. Differentiation in a Standards War: } \\
56 \mathrm{~K} \text { Modems }\end{array}$ & $3 / 04$ \\
\hline 10335 & Claudia Goldin & $\begin{array}{l}\text { From the Valley to the Summit: } \\
\text { The Quiet Revolution that Transformed Women's Work }\end{array}$ & $3 / 04$ \\
\hline 10336 & $\begin{array}{l}\text { Marcio Garcia } \\
\text { Roberto Rigobon }\end{array}$ & $\begin{array}{l}\text { A Risk Management Approach to Emerging Market's } \\
\text { Sovereign Debt Sustainability with an Application } \\
\text { to Brazilian Data }\end{array}$ & $3 / 04$ \\
\hline 10337 & $\begin{array}{l}\text { Mihir A. Desai } \\
\text { C. Fritz Foley } \\
\text { James R. Hines Jr. }\end{array}$ & $\begin{array}{l}\text { Capital Controls, Liberalizations, and } \\
\text { Foreign Direct Investment }\end{array}$ & $3 / 04$ \\
\hline 10338 & $\begin{array}{l}\text { Orazio Attanasio } \\
\text { Erich Battistin } \\
\text { Hidehiko Ichimura }\end{array}$ & $\begin{array}{l}\text { What Really Happened to Consumption Inequality } \\
\text { in the US? }\end{array}$ & $3 / 04$ \\
\hline 10339 & $\begin{array}{l}\text { Kohei Komamura } \\
\text { Atsuhiro Yamada }\end{array}$ & $\begin{array}{l}\text { Who Bears the Burden of Social Insurance?: Evidence } \\
\text { from Japanese Health and Long-term Care Insurance De }\end{array}$ & $\begin{array}{l}3 / 04 \\
\text { ata }\end{array}$ \\
\hline 10340 & $\begin{array}{l}\text { Olivia S. Mitchell } \\
\text { John Piggott }\end{array}$ & Unlocking Housing Equity in Japan & $3 / 04$ \\
\hline 10341 & Steven Shavell & $\begin{array}{l}\text { Minimum Asset Requirements and Compulsory } \\
\text { Liability Insurance As Solutions to the Judgment-Proof Pro }\end{array}$ & $\begin{array}{r}3 / 04 \\
\text { oblem }\end{array}$ \\
\hline 10342 & $\begin{array}{l}\text { Alberto Alesina } \\
\text { Roberto Perotti }\end{array}$ & The European Union: A Politically Incorrect View & $3 / 04$ \\
\hline 10343 & $\begin{array}{l}\text { William N. Goetzmann } \\
\text { Massimo Massa } \\
\text { Andrei Simonov }\end{array}$ & Portfolio Diversification and City Agglomeration & $3 / 04$ \\
\hline 10344 & $\begin{array}{l}\text { Jonathan Eaton } \\
\text { Samuel Kortun } \\
\text { Francis Kramarz }\end{array}$ & $\begin{array}{l}\text { Dissecting Trade: Firms, Industries, } \\
\text { and Export Destinations }\end{array}$ & $3 / 04$ \\
\hline 10345 & $\begin{array}{l}\text { Jay Bhattacharya } \\
\text { Darius Lakdawalla }\end{array}$ & Time-Inconsistency and Welfare & $3 / 04$ \\
\hline 10346 & B. Zorina Khan & $\begin{array}{l}\text { Technological Innovations and Endogenous } \\
\text { Changes in U.S. Legal Institutions, } 1790-1920\end{array}$ & $3 / 04$ \\
\hline 10347 & $\begin{array}{l}\text { Dirk Krueger } \\
\text { Jessica Tjornhom Donohue }\end{array}$ & $\begin{array}{l}\text { On the Distributional Consequences of Child } \\
\text { Labor Legislation }\end{array}$ & $3 / 04$ \\
\hline 10348 & $\begin{array}{l}\text { Josh Lerner } \\
\text { Antoinette Schoar }\end{array}$ & Transaction Structures in the Developing World & $3 / 04$ \\
\hline
\end{tabular}


To order any of these papers in hard copy, see instructions at the end of this list. To subscribe to all NBER Working Papers or the papers in a single area, see instructions inside the back cover.

\begin{tabular}{|c|c|c|c|}
\hline Number & $\underline{\text { Author(s) }}$ & $\underline{\text { Title }}$ & $\underline{\text { Date }}$ \\
\hline 10349 & George J. Borjas & $\begin{array}{l}\text { Do Foreign Students Crowd Out Native Students from } \\
\text { Graduate Programs? }\end{array}$ & $3 / 04$ \\
\hline 10350 & $\begin{array}{l}\text { Rachel M. Hayes } \\
\text { Paul Oyer } \\
\text { Scott Schaefer }\end{array}$ & $\begin{array}{l}\text { Co-Worker Complementarity and the Stability } \\
\text { of Top Management Teams }\end{array}$ & $3 / 04$ \\
\hline 10351 & $\begin{array}{l}\text { V.V. Chari } \\
\text { Patrick J. Kehoe } \\
\text { Ellen R. McGrattan }\end{array}$ & Business Cycle Accounting & $3 / 04$ \\
\hline 10352 & William N. Goetzmann & Fibonacci and the Financial Revolution & $3 / 04$ \\
\hline 10353 & $\begin{array}{l}\text { Ximena Clark } \\
\text { David Dollar } \\
\text { Alejandro Micco }\end{array}$ & $\begin{array}{l}\text { Port Efficiency, Maritime Transport Costs, } \\
\text { and Bilateral Trade }\end{array}$ & \\
\hline 10354 & Raj Chetty & Interest Rates and Backward-Bending Investment & $3 / 04$ \\
\hline 10355 & $\begin{array}{l}\text { Kenneth A. Froot } \\
\text { Melvyn Teo }\end{array}$ & Equity Style Returns and Institutional Investor Flows & $3 / 04$ \\
\hline 10356 & Paul R. Bergin & $\begin{array}{l}\text { How Well Can the New Open Economy Macroeconomi } \\
\text { Explain the Exchange Rate and Current Account? }\end{array}$ & \\
\hline 10357 & Susan M. Dynarski & $\begin{array}{l}\text { Tax Policy and Education Policy: } \\
\text { Collision or Coordination? } \\
\text { A Case Study of the } 529 \text { and Coverdell Saving Incentive }\end{array}$ & $3 / 04$ \\
\hline 10358 & $\begin{array}{l}\text { Philippe Aghion } \\
\text { Peter Howitt } \\
\text { David Mayer-Foulkes }\end{array}$ & $\begin{array}{l}\text { The Effect of Financial Development on Convergence: } \\
\text { Theory and Evidence }\end{array}$ & $3 / 04$ \\
\hline 10359 & Charles F. Manski & Interpreting the Predictions of Prediction Markets & $3 / 04$ \\
\hline 10360 & José De Gregorio & Productivity Growth and Disinflation in Chile & $3 / 04$ \\
\hline 10361 & Daniel S. Hamermesh & Subjective Outcomes in Economics & $3 / 04$ \\
\hline 10362 & $\begin{array}{l}\text { Troy Davig } \\
\text { Eric M. Leeper } \\
\text { Hess Chung }\end{array}$ & Monetary and Fiscal Policy Switching & $3 / 04$ \\
\hline 10363 & $\begin{array}{l}\text { Luís Cabral } \\
\text { Ali Hortaçsu }\end{array}$ & $\begin{array}{l}\text { The Dynamics of Seller Reputation: Theory and Evidenc } \\
\text { from eBay }\end{array}$ & e $3 / 04$ \\
\hline 10364 & $\begin{array}{l}\text { Stephen N. Broadberry } \\
\text { Douglas A. Irwin }\end{array}$ & $\begin{array}{l}\text { Labor Productivity in the United States and the United } \\
\text { Kingdom During the Nineteenth Century }\end{array}$ & $3 / 04$ \\
\hline
\end{tabular}


To order any of these papers in hard copy, see instructions at the end of this list. To subscribe to all NBER Working Papers or the papers in a single area, see instructions inside the back cover.

$\begin{array}{ll}\text { Number } & \text { Author(s) } \\ 10365 & \begin{array}{l}\text { David Card } \\ \text { Carlos Dobkin } \\ \text { Nicole Maestas }\end{array} \\ & \begin{array}{l}\text { David Card } \\ \text { Alan B. Krueger }\end{array} \\ & \\ 10366 & \text { Marcela Eslava } \\ & \text { John Haltiwanger } \\ & \text { Adriana Kugler } \\ & \text { Maurice Kugler } \\ 10367 & \text { Ricardo J. Caballero } \\ & \text { Eduardo M.R.A Engel } \\ 10368 & \text { Eric Bettinger } \\ & \text { Bridget Terry Long } \\ 10369 & \text { Eric Bettinger } \\ & \text { Bridget Terry Long } \\ 10370 & \text { Roland Bénabou } \\ 10371 & \text { Michael W.Brandt } \\ 10372 & \text { Pedro Santa-Clara } \\ & \text { Andrew K. Rose } \\ 10373 & \text { Jonathan Gruber } \\ & \text { Nuno Limâo } \\ & \end{array}$

$\underline{\text { Title }}$

Date

The Impact of Nearly Universal Insurance Coverage on $\quad 3 / 04$ Health Care Utilization and Health: Evidence from Medicare

Would the Elimination of Affirmative Action Affect $3 / 04$ Highly Qualified Minority Applicants? Evidence from California and Texas

The Effect of Structural Reforms on Productivity and Profitability Enhancing Reallocation: Evidence from Colombia

Three Strikes and You're Out: Reply to Cooper and Willis 3/04

Shape Up or Ship Out: The Effects of Remediation on $\quad 3 / 04$ Students at Four-Year Colleges

Do College Instructors Matter? The Effects of Adjuncts 3/04 and Graduate Assistants on Students' Interests and Success

Inequality, Technology, and the Social Contract $\quad 3 / 04$

Dynamic Portfolio Selection by Augmenting the Asst $\quad 3 / 04$ Space

A Meta-Analysis of the Effect of Common Currencies on 3/04 International Trade

Pay or Pray? The Impact of Charitable Subsidies on $\quad 3 / 04$ Religious Attendance

Government Gains from Self-Restraint: A Bargaining 3/04 Theory of Inefficient Redistribution

Copies of the above working papers can be obtained for $\$ 10.00$ per copy (plus $\$ 10.00$ per order for shipping for all locations outside the continental U.S.) to Working Papers, NBER, 1050 Massachusetts Avenue, Cambridge, MA 021385398. Pre-payment is required on all orders and may be made by check or credit card. Checks should be made payable to the NBER and must be in dollars drawn on a U.S. bank. If paying by credit card, include the cardholder's name, account number, and expiration date. For all orders, please be sure to include your return address and telephone number. Working papers may also be ordered by telephone (868-3900), fax (617-868-2742), or email (orders@,nber.org). 